\title{
Mutation of the cytosolic ribosomal protein-encoding RPS10B gene affects shoot meristematic function in Arabidopsis
}

Petra Stirnberg ${ }^{1}$, Jin-Ping Liu' ${ }^{1,2}$, Sally Ward ${ }^{1,3}$, Sarah L Kendall ${ }^{1,4}$ and Ottoline Leyser ${ }^{1,3^{*}}$

\begin{abstract}
Background: Plant cytosolic ribosomal proteins are encoded by small gene families. Mutants affecting these genes are often viable, but show growth and developmental defects, suggesting incomplete functional redundancy within the families. Dormancy to growth transitions, such as the activation of axillary buds in the shoot, are characterised by co-ordinated upregulation of ribosomal protein genes.

Results: A recessive mutation in RPS10B, one of three Arabidopsis genes encoding the eukaryote-specific cytoplasmic ribosomal protein S10e, was found to suppress the excessive shoot branching mutant max2-1. rps10b-1 mildly affects the formation and separation of shoot lateral organs, including the shoot axillary meristems. Axillary meristem defects are enhanced when rps10b-1 is combined with mutations in REVOLUTA, AUXIN-RESISTANT1, PINOID or another suppressor of max2-1, FAR-RED ELONGATED HYPOCOTYL3. In some of these double mutants, the maintenance of the primary shoot meristem is also affected. In contrast, mutation of ALTERED MERISTEM PROGRAMME1 suppresses the rps10b-1axillary shoot defect. Defects in both axillary shoot formation and organ separation were enhanced by combining rps 10b-1 with cuc3, a mutation affecting one of three Arabidopsis NAC transcription factor genes with partially redundant roles in these processes. To assess the effect of rps10b-1 on bud activation independently from bud formation, axillary bud outgrowth on excised cauline nodes was analysed. The outgrowth rate of untreated buds was reduced only slightly by rps $106-1$ in both wild-type and max2-1 backgrounds. However, rps 10b-1 strongly suppressed the auxin resistant outgrowth of max2-1 buds. A developmental phenotype of rps10b-1, reduced stamen number, was complemented by the cDNA of another family member, RPS10C, under the RPS10B promoter.

Conclusions: RPS1OB promotes shoot branching mainly by promoting axillary shoot development. It contributes to organ boundary formation and leaf polarity, and sustains max2-1 bud outgrowth in the presence of auxin. These processes require the auxin response machinery and precise spatial distribution of auxin. The correct dosage of protein(s) involved in auxin-mediated patterning may be RPS1OB-dependent. Inability of other RPS10 gene family members to maintain fully S10e levels might cause the rps10b-1 phenotype, as we found no evidence for unique functional specialisation of either RPS1OB promoter or RPS10B protein.
\end{abstract}

Keywords: Shoot branching suppressor, S10e, Axillary bud, Leaf polarity, Lateral organ boundary, Auxin, Strigolactone, CUC, REV

\footnotetext{
* Correspondence: ol235@cam.ac.uk

'Department of Biology, University of York, Wentworth Way, York YO10 5DD, UK

${ }^{3}$ Present Address: Sainsbury Laboratory, Cambridge University, Bateman Street, Cambridge CB2 1LR, UK

Full list of author information is available at the end of the article
} 


\section{Background}

Shoot branching exemplifies two characteristic aspects of plant development. First, the body plan is generated by the production of repetitive modules. Second, the timing of the initiation, subsequent growth, and the final morphology of these modules are flexible and responsive to internal and external cues. This second aspect suggests that plants possess mechanisms to modulate their cellular growth machinery, including complex and energy-demanding processes such as ribosomal biogenesis, cell divison and cell expansion.

During post-embryonic growth of the shoot, secondary shoot meristems can generate new growth axes. These secondary meristems include leaf-associated, branchforming axillary meristems, and reproductive, floral meristems [1]. In many respects, these secondary meristems resemble the primary shoot meristem, which gives rise to the primary shoot axis. A common set of regulatory genes acts in their formation and patterning [2]. Few genes, such as the Arabidopsis $R A X$ family $[3,4]$ seem to function exclusively in the formation of secondary shoot meristems, possibly as position specific initiators of the shoot meristematic programme. Some of the common functions are encoded by small gene families whose members vary in their contribution with respect to meristem position, such that mutation of one family member results in a secondary shoot meristem-specific phenotype. For example. in Arabidopsis, loss of REVOLUTA (REV), one of a family of five class III HOMEODOMAIN LEUCINE ZIPPER (HDZIPIII) transcription factor genes, leads to partial loss of axillary meristems and causes premature arrest of some floral meristems [5,6]. However, if two other family members, PHAVOLUTA and PHABU$L O S A$, are mutated in addition to $R E V$, the embryonic shoot meristem fails to form $[7,8]$. Similarly, within the three-member CUP-SHAPED COTYLEDON (CUC) gene family, $\mathrm{CUC} 2$ and $\mathrm{CUC} 3$ overlap in axillary meristem formation, while all three genes contribute to the formation of the primary shoot meristem [9-12].

Secondary shoot meristems initiate in zones where CUC and HDZIPIII expression overlap [2]. Postembryonic $C U C$ expression strongly marks the boundaries of initiating lateral organs and has also been detected, at a low level, at the meristem centre $[10,11,13,14]$. CUC3 for example, marks the adaxial boundary of developing leaf primordia, where secondary meristems will form [12]. HDZIPIII expression is initially continuous, spanning the meristem centre and the adaxial half of initiating leaves, but the leaf domain separates with its displacement from the growing meristem summit $[6,15]$. The abaxial side of organ primordia is marked by expression of genes from the four-member KANADI (KAN) family. These may limit shoot meristematic activity, because ectopic $K A N$ expression abolishes shoot meristem formation, and multiple loss-of function kan seedlings form ectopic lateral organs [16-19]. While these and a number of other transcription factor genes are clearly involved in establishing and patterning shoot meristems, it is less clear whether and how they affect the rate of meristematic growth and organ production. For example, HDZIPIII family members appear to regulate the size of the central stem-cell containing zone in shoot meristems [8,20-22], and this might affect meristem activity. CUC expression marks zones of reduced growth within the shoot meristem [23], but also in other tissues [24].

Many of the axillary shoot meristems initiated during the lifetime of a plant cease growing after a short period, forming a small dormant bud in the leaf axil. Due to their ability to resume growth rapidly in response to an activating signal, axillary buds have been used as a model to study the regulation of meristematic activity in plants. Subtractive gene cloning in pea, and microarray analysis in Arabidopsis, show that bud activation involves a rapid, strong and coordinate upregulation of cell-cycle and protein synthesis-related genes, including many ribosomal protein (r-protein) genes, which precedes the onset of growth $[25,26]$. Analysis of the promoter motifs shared by these genes points to possible control by members of the TCP (TEOSINTE BRANCHED / CYCLODEA / PROLIFERATING CELL FACTORS 1 and 2) transcription factor family [26]. Of the two types of TCPs, class I is associated with growth activation and class II with growth arrest; and the DNA binding motifs identified for each class overlap partially, raising the possibility of competitive regulation via shared promoter elements [27]. In support of a role of TCPs in axillary bud growth control, loss of function of axillary shoot-meristem-specific class II TCPs, such as the BRANCHED1 (BRC1) and BRC2 genes of Arabidopsis, is associated with constitutive bud activation $[28,29]$. The correlation between the expression of such budspecific class II TCP genes and the extent of bud growth repression is generally good, but not absolute [30]. One possible explanation for this is the involvement of coregulators of bud growth such as positively-acting TCPs.

The plant hormone auxin plays a dual role in shoot meristem growth, acting both locally along with patterning genes within the meristem, and as a long-distance signal to coordinate meristem activities within the shoot. Its patterning role has been clarified in the last decade. Transient local auxin maxima form and induce lateral organ formation in the peripheral zone of shoot meristems. These are created through directional auxin transport involving PIN1 and possibly other members of the PIN-formed protein family [31]. The protein kinase PINOID [32] is required for the observed dynamic directional changes in PIN plasma membrane localisation 
and auxin transport direction [33,34]. Organogenesis is thought to be induced via auxin-receptor mediated activation of members of the AUXIN RESPONSE FACTOR (ARF) transcription factor family [35], several of which are expressed at the shoot apex [36]. These might, directly or indirectly, modulate the expression of meristem patterning genes. For example, auxin-mediated repression is thought to restrict CUC expression to the boundaries of initiating organs [37]. In contrast, some HD-ZIPIII family members are auxin-induced [38].

Lateral organ development is accompanied by an inward movement of auxin through the centre of the organ primordium towards the vasculature in the subtending shoot axis $[39,40]$. It is thought that this triggers vascular differentiation in an interplay with the adaxial $H D Z I P I I I$, abaxial $K A N$, and ARF genes expressed within this zone $[41,42]$, and establishes continuity with the pre-existing vasculature, in which auxin moves in a strictly basipetal (shoot-to-root) direction in the xylem parenchyma. Interestingly auxin moving in this polar transport stream (PATS) in the shoot axis has long been known to inhibit axillary shoot meristem activity in an indirect manner. These observations have been integrated into a model where both apical and axillary shoot meristem activities are governed by the ability to canalize auxin transport from developing organ primordia into pre-existing vasculature [43-45]. In addition, auxin in the PATS seems to control the production of other signals, which move root-to-shootwards in the xylem and might enter axillary shoots and regulate their growth. Auxin suppresses the biosynthesis of cytokinins $[46,47]$, which can promote the growth of axillary buds when directly applied to them [48], and promotes the biosynthesis of the recently-discovered strigolactones [49-52], which can inhibit axillary buds upon direct application [53].

more axillary growth2-1 (max2-1) is a strigolactone signalling mutant which shows constitutive axillary bud activation [54-56]. In a screen for second-site $\operatorname{max2-1}$ branching suppressors, we unexpectedly identified a mutation in $R P S 10 B$, one of three genes encoding protein $\mathrm{S} 10 \mathrm{e}$ of the cytoplasmic ribosome, whose role in supporting shoot meristematic function we describe here.

\section{Results}

\section{A recessive mutation in cytosolic ribosomal protein RPS10B partially suppresses $\max 2-1$}

The strigolactone-insensitive $\max 2-1$ mutant produces an excessive number of inflorescence branches from rosette leaf axils [54]. To identify novel regulators of shoot branching, we performed a suppressor screen in this genetic background. In one of the isolates, 6-7, a recessive, second-site mutation, significantly reduced rosette branching. In addition, 6-7 shoots were slightly taller than $\max 2-1$ and their primary inflorescences had a slightly higher number of cauline, leaf-bearing nodes (Figure 1a, b). We temporarily named the suppressor mutation in this line 6-7. After backcrossing 6-7 to wild-type Columbia, these traits were also detected in the wild-type MAX2 background, although the effect on branching was less striking, and could not be readily used to map the suppressor. A pointed juvenile leaf phenotype that co-segregated with the branching habit was instead used (Figure 1c, d). 6-7 was crossed to Landsberg-erecta, and the locus was mapped to a $126 \mathrm{~kb}$ region on chromosome 5 by assessing cosegregation of DNA polymorphisms between Landsberg and Columbia in mutant individuals from the $F_{2}$ of this cross. JAtY TAC library clones in pYLTAC17 [57] containing large wild-type genomic inserts from the mapping interval were transformed into the mutant and assessed for rescue. This defined six candidate genes, whose coding regions were amplified from 6-7 and sequenced (Figure 1e). The sole divergence from wild type was a $G$ to A transition, which introduced a premature termination codon in At5g41520 (RPS10B), one of three Arabidopsis genes encoding cytoplasmic ribosomal protein S10e. RPS10B transcript level was lower in 6-7 than in the wild type (Figure 1f), suggesting nonsense-mediated decay. Identity of $R P S 10 B$ as the suppressor gene was confirmed by mutant rescue with a wild-type $R P S 10 B$ genomic construct (Additional file 1: Table S1), and the mutant allele was named rps10b-1.

\section{rps10b-1 affects axillary shoot initiation and growth}

With wild-type Columbia plants grown in long photoperiods, floral transition is the trigger for axillary shoot initiation. The axillary shoots activate to form inflorescence branches in an apical-basal wave, i.e. from the cauline leaf axils, situated along the primary inflorescence, towards the rosette leaf axils [58]. In the wild type, only a few of the topmost rosette leaf axils produce branches, while more basal rosette axils carry arrested buds. In max2-1, neither the timing of axillary shoot initiation nor the outgrowth sequence is altered, but nearly all the rosette axils produce a branch [54].

The rps10b-1 mutation caused a reduction in axillary shoot size at equivalent nodal positions in the rosettes of both MAX2 and max2-1 plants (Figure 2a-d). In addition, one or two axils at the top of the rosette often appeared to be empty. A small proportion of the rps10b-1 cauline leaf axils were also empty (Figure $2 \mathrm{e}-\mathrm{g}$, Table 1 ), and remained so until maturity. This indicates that rps10b-1 affects axillary shoot initiation. Either a delay in axillary shoot formation, or an additional effect on axillary bud growth rate, might cause the reduced size of rps10b-1 buds. 
To quantify these phenotypes, we examined flowering plants under a dissecting microscope and assessed axillary shoot development at consecutive nodal positions throughout the rosette. Four developmental stages were defined, and the proportions of rosette axils at each stage were calculated for ten individual plants per genotype (average proportions \pm SEM shown in Figure $2 \mathrm{~h}$ ). The stages were defined as follows: 1 . Branches (inflorescence length above $3 \mathrm{~mm}$ ), 2. Big axillary buds whose inflorescence had not yet significantly elongated. 3 . Small buds with leaf primordia clearly visible but shorter than $2 \mathrm{~mm}$. 4. Apparently empty axils lacking visible axillary leaf primordia (it was not possible at the magnification used to determine whether an axillary meristem had been initiated or not). The frequency of class 4 was negligible in both wild-type and $\max 2-1$ rosettes, but these genotypes differed with respect to the proportions of the three more advanced classes. Compared to the wild type, $\max 2-1$ showed a dramatic increase in the most advanced class, balanced by a decrease of the two intermediate classes. In contrast, for $r p s 10 b-1$ in both the MAX2 and max2-1 backgrounds, the proportion occupied by the most advanced class decreased, and this was balanced by an increase in the proportion of apparently empty axils, with little change in the intermediate classes. These results indicate that RPS10B promotes axillary shoot development from an early stage, including both axillary bud formation and possibly subsequent bud growth. In contrast, MAX2 represses only the later stages of bud activity [54], suggesting that $R P S 10 B$ acts at least in part independently of $M A X 2$.

To assess whether rps10b-1 affects axillary shoot growth independently from initiation, we studied the outgrowth kinetics of axillary inflorescences on isolated cauline nodes. Nodal explants, consisting of a cauline axillary bud smaller than $2 \mathrm{~mm}$ and $5-7 \mathrm{~mm}$ of the primary inflorescence stem above and below the node, were inserted between two agar slabs in a Petri dish (as described in [59]). The length of the axillary buds was monitored over a 10 day period. rps $10 b-1$ caused a slight delay in inflorescence outgrowth in both MAX2 and max2-1 backgrounds (Figure 3a, solid lines).

\section{rps10b-1 does not restore strigolactone responses to max2-1, but confers auxin-related phenotypes antagonistic to those of $\operatorname{max2-1}$}

In addition to increased branching, the max2-1 mutant has a range of phenotypes associated with its strigolactone
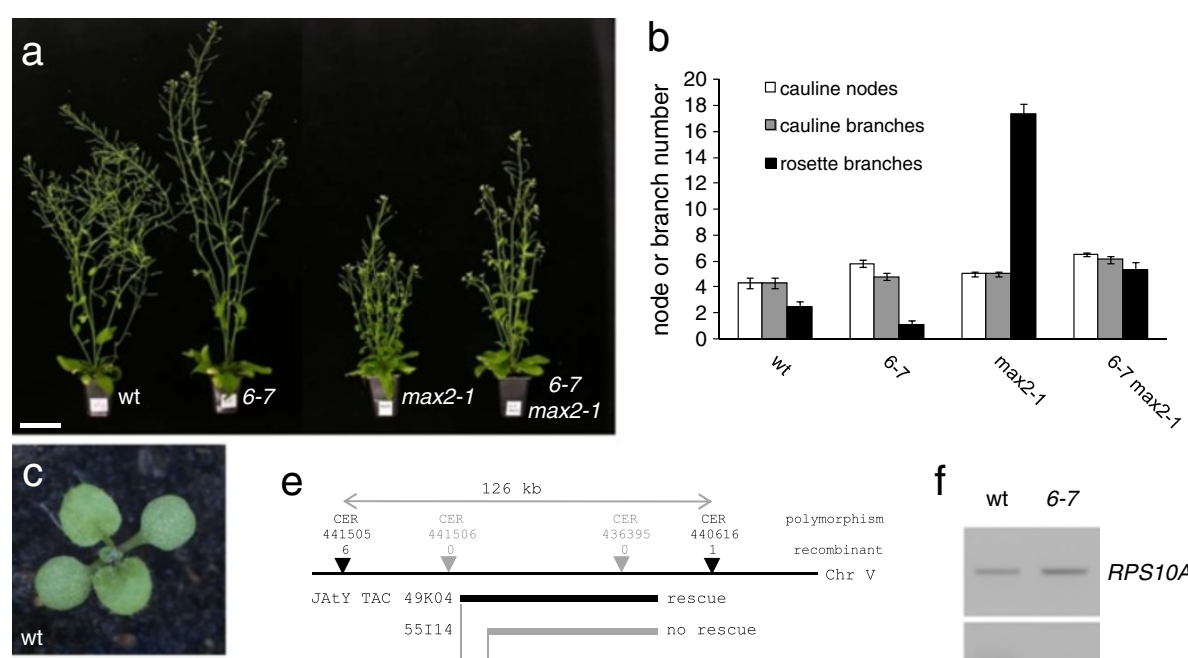

e
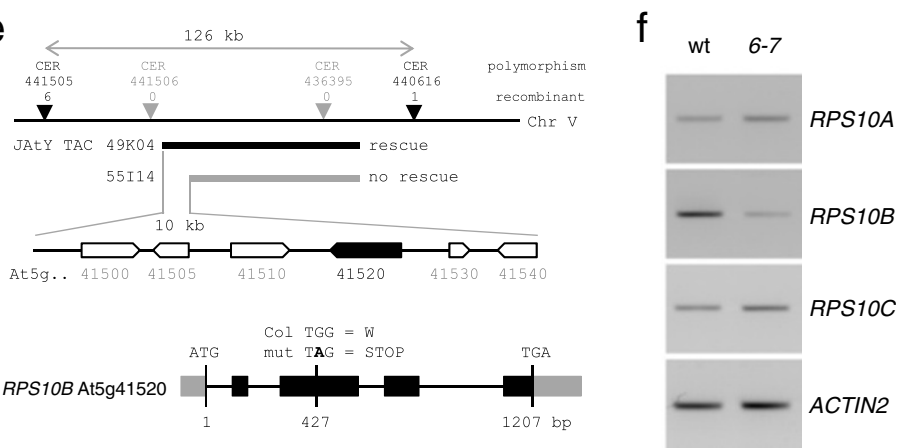

Figure 1 6-7, a partial suppressor of max2-1, affects ribosomal protein gene RPS10B. (a,b) Effect of 6-7 on shoot architecture and branching in the wild-type MAX2 and in the max2-1 mutant background. (a) Plants aged 6 weeks. Scale bar: $5 \mathrm{~cm}$. (b) Number of cauline nodes, cauline branches and rosette branches $(\geq 0.5 \mathrm{~cm}$ ) at maturity (Average \pm SEM, $n=10)$. (c,d) The first leaves of 6-7 mutant seedlings (d) are slightly more pointed than those of wild-type (c) seedlings. (e) 6-7 carries a mutation in RPS10B, one of three Arabidopsis genes encoding ribosomal protein S10e. Gene mapping to a $126 \mathrm{~kb}$ interval on chromosome 5. Population size: about 1600 mutant individuals. Mutant rescue by JAtY TAC clone 49 K04, but not by 55114, defined six candidate genes. Only one of these, RPS10B, carried a nonsense mutation in its coding region. (f) RT-PCR analysis showing reduced RPS10B transcript levels in 6-7. The primers used for RT-PCR are given in Table 5. 

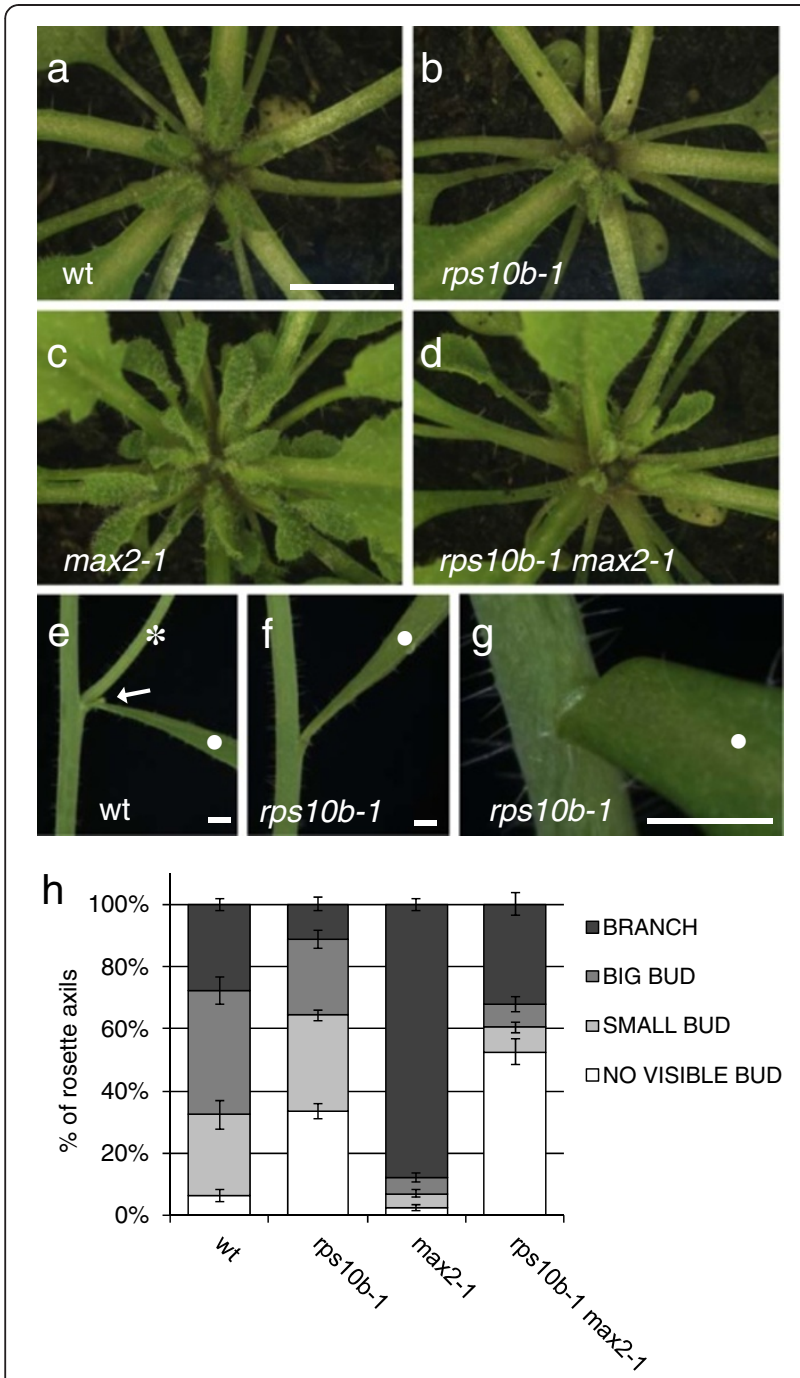

Figure 2 rps 10b-1 affects axillary bud initiation and growth in the wild-type and the max2-1 mutant backgrounds. (a-d) Rosette centres seen from above at early flowering stage. The primary inflorescences were between 1.7 and $2 \mathrm{~cm}$ long and were removed to reveal the rosette leaf axils. Scale bar in (a) for (a-d) $5 \mathrm{~mm}$. (e-g) rps10b-1 affects axillary shoot formation at cauline nodes. Scale bars in (e-g) $2 \mathrm{~mm}$. (e) Wild-type cauline node with a leaf (white dot), a cauline branch (white star) and a small accessory axillary bud (white arrow). (f,g) Some cauline leaf axils of rps10b-1 appear empty. (h) Quantitative analysis of rosette axillary shoot development at the reproductive stage (when the tenth flower on the primary inflorescence opened). For ten rosettes per genotype, all the leaf axils were examined under a dissecting microscope and the developmental stage of the axillary shoots scored into four classes given in the key (defined in detail in the Results section). The percentages of rosette nodes occupied by each class were calculated for each individual plant and the average percentages $( \pm$ SEM) for each genotype are shown.

insensitivity. These include an elongated hypocotyl and overexpression of the strigolactone biosynthetic genes CAROTENOID CLEAVAGE DIOXYGENASE7 (CCD7) and $C C D 8$, which are feedback-downregulated by strigolactone signalling $[52,55,56]$. In a hypocotyl growth inhibition assay, rps10b-1 did not suppress the strigolactone insensitivity of $\max 2-1$ (Additional file 2: Figure S1). Furthermore, rps10b-1 did not affect levels of $C C D 7$ or $C C D 8$ transcript characteristic of the MAX2or max2-1-backgrounds (Additional file 3: Figure S2). Therefore, the suppression of $\max 2-1$ by rps $10 b-1$ is specific to axillary shoot growth and does not involve a global restoration of strigolactone responsiveness.

Auxin has been implicated in both axillary meristem initiation and outgrowth. Furthermore, max2-1, in common with other strigolatone mutants, displays a number of auxin-related phenotypes, which led to the hypothesis that strigolactones act by restricting polar auxin transport. We therefore assessed the effect of rps10b-1 on these auxin-related phenotypes. The outgrowth of wildtype buds is strongly delayed by apical supply of the synthetic auxin naphthalene acetic acid (NAA), but $\max 2-1$ axillary buds are resistant to this auxin effect $[55,59,60]$ (Figure 3a). In the wild-type background, rps10b-1 delayed outgrowth only slightly, similar to its effect in the absence of auxin. However, in combination with max2-1, rps10b-1 substantially delayed bud outgrowth, such that the outgrowth of double mutant buds on auxin-treated explants was nearly identical to wild-type buds. Thus, rps10b-1 suppresses max2-1 bud auxin resistance.

A second auxin-related phenotype of $\max 2-1$ is an increase in basipetal transport of radiolabeled auxin through primary inflorescence stem segments $[55,60]$. We found that rps10b-1 did not affect this phenotype (Figure $3 b$ ). Rather, the mutation slightly increased the amount of auxin transported in both MAX2 and max2-1 backgrounds.

Third, the auxin response reporter construct DR5::GUS [61] has increased activity in the main shoot axis of $\max 2-1$ plants [60], associated with increased amounts of auxin moving in the PATS [44]. We found that this increase in DR5::GUS expression was partially suppressed in rps10b-1 max2-1. This effect was observed in hypocotyls from 2week old seedlings (Figure $3 \mathrm{c}-\mathrm{f}$ ) as well as hypocotyls from 9-week-old short-day grown plants, which had undergone secondary thickening (Figure $3 \mathrm{~g}-\mathrm{j}$ ). In the MAX2 background, rps10b-1 had little effect, with xylem-associated DR5::GUS activity possibly slightly increased. These differences in reporter activity do not simply reflect differences in bud activity, because the 2-week-old seedlings had not yet initiated axillary buds. In summary, rps10b-1 partially rescued some of the auxin-related phenotypes of max2-1, indicating that $R P S 1 O B$ may act by modulating auxin responsiveness or homeostasis.

\section{rps10b-1 in high-branching mutant backgrounds}

To learn more about the mode of RPS1OB action we assessed its genetic interactions with other known shoot 
Table 1 Effect of rps10b-1 on cauline vegetative node development

\begin{tabular}{|c|c|c|c|c|c|c|c|}
\hline \multirow[t]{3}{*}{ Genotype } & \multicolumn{3}{|c|}{ Axillary shoot score } & \multicolumn{3}{|c|}{ Leaf score } & \multirow[t]{3}{*}{ Nodes scored $^{\mathrm{a}}$} \\
\hline & \multicolumn{3}{|c|}{$\%$ of cauline nodes } & \multicolumn{3}{|c|}{$\%$ of cauline nodes } & \\
\hline & with branch & with bud & without bud & normal & leaf-stem fusion & without leaf & \\
\hline wild type & 100.0 & 0.0 & 0.0 & 100.0 & 0.0 & 0.0 & 153 \\
\hline rps10b-1 & 94.4 & 1.7 & 3.9 & 90.5 & 2.2 & 7.3 & 179 \\
\hline $\max 2-1$ & 100.0 & 0.0 & 0.0 & 100.0 & 0.0 & 0.0 & 163 \\
\hline rps10b-1 max2-1 & 97.3 & 0.5 & 2.3 & 96.4 & 3.2 & 0.5 & 220 \\
\hline
\end{tabular}

${ }^{a}$ The cauline vegetative nodes along the primary inflorescence of 38-40 plants per genotype were scored by the naked eye.

branching regulatory genes. First, the effect of the rps10b-1 mutation in high-branching mutant backgrounds other than $\max 2-1$ was assessed (Figure 4a). As expected, the strigolactone biosynthetic mutant $\max 4-1$ (ccd8) [62], was partially suppressed. brc1-2 and $b r c 2-1$ are loss of function alleles of bud-specific class II TCP transcription factor genes [28]. As with $\max 2$, excessive branching of $b r c 1-2$ is strigolactone-insensitive [53]. $b r c 1-2$ and the $b r c 1-2$ brc2-1 double mutant were also partially suppressed by rps10b-1. In all tested double and triple mutant combinations of $r p s 10 b-1$ with $\max 4, \operatorname{brc} 1$ or $b r c 2$, empty axils were present at apical nodes in the rosette at maturity. Thus, as with $\max 2$, at least part of the suppression by rps10b-1 in these backgrounds resulted from a defective or delayed axillary shoot formation.

Perception of auxin by the TIR1/AFB auxin receptors triggers the ubiquitin-mediated degradation of Aux/IAA proteins, which are repressors of the AUXIN RESPONSE FACTOR (ARF) transcriptional regulators [63]. This degradation requires the AUXIN-RESISTANT1 (AXR1) protein $[63,64]$. Mutation of $A X R 1$ has little effect on bud initiation, but results in increased and auxin resistant bud outgrowth [65,66]. In combination with rps10b-1, the axr1-3 mutant allele surprisingly enhanced the suppression of axillary bud development at both apical rosette (Figure $4 \mathrm{~b}-\mathrm{e}$ ) and cauline nodes. In some experiments, as shown in Figure $4 \mathrm{~b}-\mathrm{e}$, buds in these positions were considerably smaller than those of either single mutant. In other experiments, a large proportion of cauline and apical rosette axils appeared completely empty in rps10b-1 axr1-3 plants. In addition, the primary inflorescence meristem of rps10b-1 axr1-3 plants frequently aborted. Between $20 \%$ and $50 \%$ of the double mutant individuals, but neither of the single mutants, had this phenotype. These observations suggest that $R P S 10 B$ and $A X R 1$ interact to promote shoot meristem development. However, this interaction appeared to be positionally restricted. At more basal rosette nodes of double mutant plants, bud behaviour resembled the axr1single mutant; axillary buds initiated and formed inflorescence branches, such that rosette branch numbers of axr1-3 and rps10b-1 axr1-3 at maturity did not differ significantly (Figure 4a).
Mutation of $A M P 1$, which encodes a putative carboxypeptidase with unknown molecular function, causes a range of phenotypes related to shoot meristem function including constitutive axillary bud activation, increased shoot meristem size, increased rate of leaf initiation, and increased cytokinin content [67-70]. The defective axillary bud formation in apical rosette nodes typical of rps10b-1 was completely suppressed in an amp1-1 background (Figure $4 \mathrm{~b}, \mathrm{c}, \mathrm{f}-\mathrm{h}$ ), and at maturity, the average branch number of rps10b-1 amp1-1 plants did not differ significantly from amp1-1 plants. Genetic analysis by Vidaurre and coworkers [71] suggests a major function of ARF-mediated auxin signalling in embryogenic shoot meristem formation and vascularisation might be the downregulation of AMP1 activity. In the light of this finding, the genetic interaction with amp1-1 further supports the idea that reduced ARF-mediated auxin signalling is involved in the rps10b-1 meristematic phenotypes.

\section{rps10b-1 in low-branching mutant backgrounds}

We also analysed the effect of rps10b-1 in genetic backgrounds characterised by reduced branching. First, we constructed a double mutant of rps10b-1 with another non-allelic max2-1 suppressor from our screen, far-red elongated hypocotyl3-12 (fhy3-12). This is a loss-of function allele of the transcriptional activator FHY3 [72]. This mutation suppresses max2-1 by reducing bud activation, with negligible effects on axillary shoot formation; and our data suggest that auxin might be central to its branching phenotype [73]. rps10b-1 fhy3-12 double mutant plants showed a near-complete loss of rosette axillary buds (Figure 5a-d). Furthermore, the primary inflorescence meristem of double mutant plants often aborted during the reproductive phase, a phenotype not observed with either single mutant (Figure $5 \mathrm{~g}$ ). The frequency of abortion ranged from $30 \%$ to $90 \%$ in different experiments.

As described earlier, mutation of the HDZIPIII gene $R E V$ causes partial defects in axillary meristem formation and floral meristem maintenance. In addition, the HDZIPIII family members redundantly specify adaxial leaf identity, but rev loss-of-function mutant leaves appear 


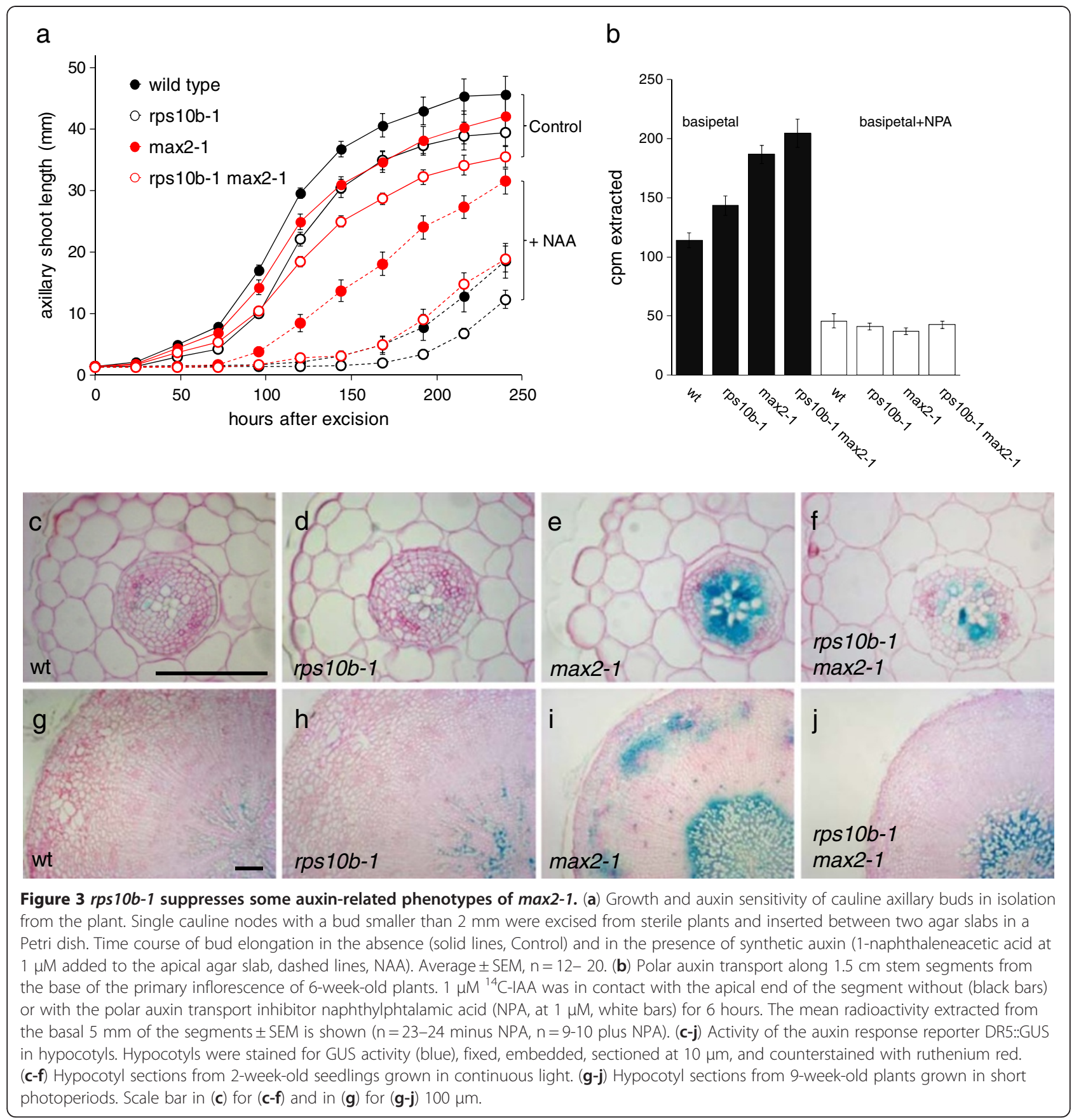

normal $[7,8]$. We generated double mutants between rps10b-1 and a rev T-DNA insertion allele, SALK 102345 (Figure 5f, h). These were highly abnormal. Successive leaves became increasingly needle-like, and axillary shoots were absent. The primary stem was short, pin-like and lacked flowers. Thus, rps10b-1 strongly enhanced the loss of $R E V$ function with respect to both leaf polarity and axillary shoot formation. The $F_{2}$ analysis also revealed that a single copy of the rev mutant allele strongly enhanced the axillary shoot phenotypes in the rps10b-1 mutant background, while rps10b-1/+ rev/+ axillary shoot development was normal (Figure 6a-e). rps10b-1 rev/+ plants had normal stature and slight defects in floral meristem maintenance. Their leaf polarity appeared largely normal, except that a few leaves had reduced lamina, from which the midvein separated as an abaxial outgrowth at the distal end of the leaf (Figure 6f, g). The strongest effect of REV haploinsufficiency concerned axillary shoot formation. Nearly all the rosette and a substantial proportion of cauline leaf axils were empty (Figure 6d, e). This demonstrates a dosage dependence of $R E V$ in the rps10b-1 background, 


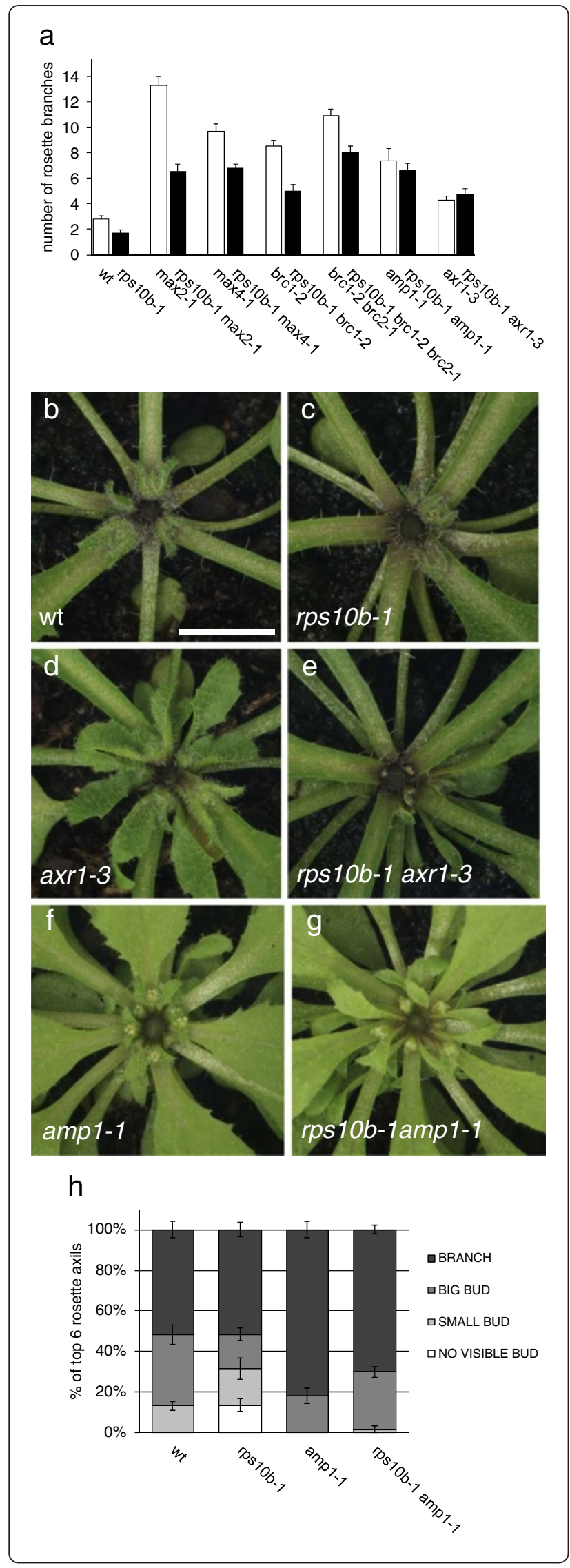

Figure 4 Interaction of rps 10b-1 with high-branching mutants. (a) Effect of rps 10b-1 on the number of rosette branches at maturity in max2-1, max4-1, brc1-2, brc1-2 brc2-1, amp1-1 and axr1-3 mutant backgrounds. Branches $\geq 0.5 \mathrm{~cm}$ were counted, average \pm SEM, n $=8-10$. (b-g) Rosette centres of selected genotypes from (a), seen from above at early flowering stage. The primary inflorescences were between 3.0 and $3.4 \mathrm{~cm}$ long and were removed to reveal the rosette leaf axils. Scale bar in (b) for (b-g) $5 \mathrm{~mm}$. (h) The rps 10b-1 bud initiation defect at apical rosette axils is rescued in the rps10b-1 amp1-1 double mutant. Quantitative analysis of rosette axillary shoot development at the reproductive stage was carried out as in Figure 2h, but only the topmost six rosette leaf axils of each plant were scored, $n=10-11$.

which is not seen in the wild-type RPS1OB background, where rev appeared recessive.

The PID protein kinase is required for dynamic changes in plasma-membrane localisation of PIN auxin transporters and thereby auxin transport direction [32-34,74]. Plants homozygous for strong pid mutant alleles are defective in flower formation, and the few flowers produced are abnormal and sterile [75]. We crossed rps10b-1 with a pid-14 heterozygote (SALK_049736 [34,76]) and homozygous double mutants were identified in segregating rps10b-1 pid-14/+ $\mathrm{F}_{3}$ families (Figure 6h-k). In addition to the defect in flower formation, which has been described, homozygous pid-14 segregants from RPS10B pid-14/+ control $\mathrm{F}_{3}$ families showed mild defects in cauline and axillary bud initiation similar to the rps10b-1 single mutant. pid-14 heterozygotes from the control $\mathrm{F}_{3}$ were indistinguishable from PID segregants and wild-type controls. The double mutants segregating in the progeny of rps10b-1 pid-14/+ plants had a more severe phenotype than pid-14 alone, as neither cauline leaves nor branches, nor flowers were produced on the primary inflorescence, and the proportion of empty rosette axils was increased. Furthermore rps10b-1 pid-14/+ $\mathrm{F}_{3}$ individuals also showed slightly enhanced axillary shoot defects when compared with rps10b-1 PID $\mathrm{F}_{3}$ segregants or rps10b-1 controls. The proportions of empty cauline and rosette axils were increased (Figure 6k). Although less striking than with $R E V$, there is a PID dosage effect in the rps10b-1 background, demonstrating that partial loss of this $r$-protein increases sensitivity to reduced function of both PID and REV.

\section{RPS10B supports CUC gene function}

As described above, rps10b-1caused failure of the primary shoot meristem or of floral meristems in some mutant backgrounds. This could point to a more general role of $R P S 1 O B$ in supporting shoot meristematic function, which is also indicated by other weakly penetrant traits observed with the rps10b-1 single mutant. In rps10b-1 flowers, the number, identity and separation of lateral organs were affected (Figure 7). Sepal, petal, 


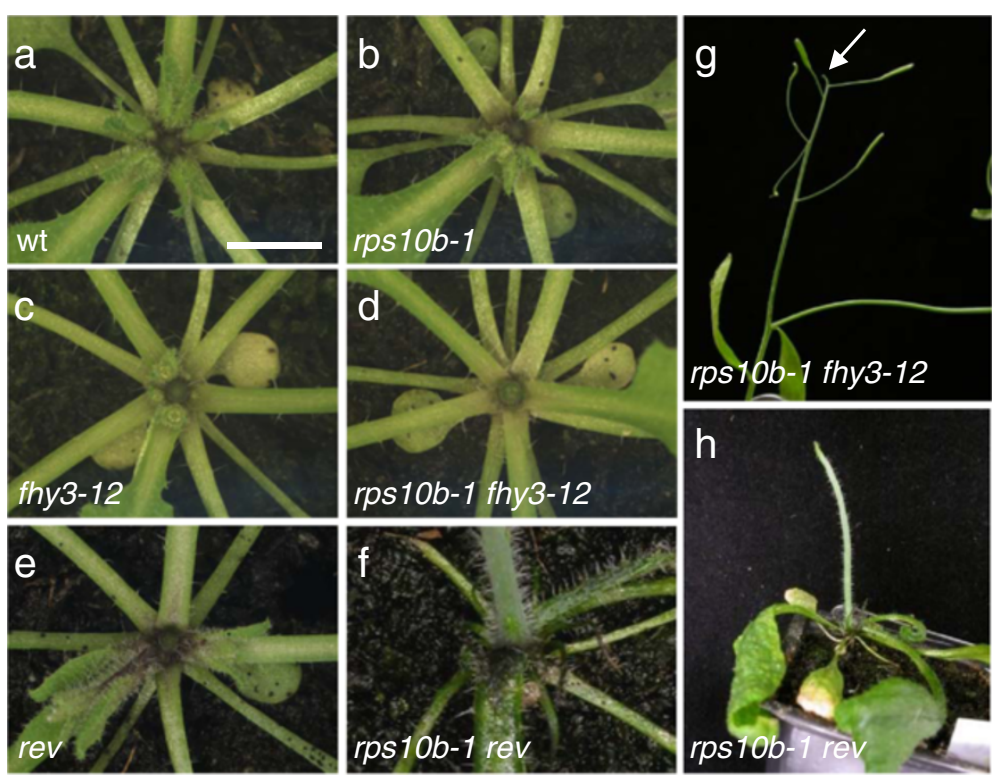

Figure 5 Interaction of rps10b-1 with the low-branching mutants fhy3-12 and rev. (a-f) Rosette centres of wild-type, single and double mutant plants at early flowering stage. Except for rps10b-1 rev (SALK_102345), the primary inflorescences were removed to reveal the rosette leaf axils. Note the complete absence of rosette axillary buds in rps10b-1 fhy3-12 and rps10b-1 rev, and the filament-like lateral organs at the top of the rps 10b-1 rev rosette which are likely the youngest, radialised leaves. $(\mathbf{g}, \mathbf{h})$ Other shoot-meristem-related phenotypes of double mutant plants. (g) Abortion of the primary inflorescence meristem of an rps10b-1 fhy3-12 plant in a short, pin-like structure (arrow). (h) rps 10b-1 rev primary inflorescences were pin-like and lacked lateral organs.

stamen and carpel numbers were more variable than in the wild type (Table 2). A substantial proportion of rps10b-1 flowers lacked one stamen, while petal and carpel numbers were more often increased than decreased (Figure $7 \mathrm{a}-\mathrm{d}$ ). Fusion between organs in one whorl was sometimes detected, most frequently for the stamens (Figure 7e). Furthermore, some stamens were green and possibly carpelloid (Figure $7 \mathrm{f}$ ) and/or were partly fused to the gynoeceum (Figure $7 \mathrm{~g}-\mathrm{h}$ ).

Furthermore, patterning defects in addition to the lack of axillary shoots were observed at cauline nodes at low frequencies (Figure $8 \mathrm{a}-\mathrm{c}$, Table 1). The topmost cauline branches of rps10b-1 were occasionally not subtended by a cauline leaf (Figure 8c), and fusion of cauline leaf lamina to the inflorescence stem was sometimes detected (Figure 8b).

Such phenotypes suggest a role of RPS1OB in lateral organ partitioning and separation. To test this hypothesis, we studied the genetic interaction between RPS10B with $C U C 3$, one of three NAC transcription factor family members with partially overlapping roles in organ boundary formation. An rps10b-1 cuc3 double mutant was constructed using a T-DNA knockout allele of $c u c 3$ (GABI-KAT line GK_302G09 [77]). With respect to cauline node development (Table 3 and Figure 8a, d, e), cuc3 was nearly indistinguishable from wild type, consistent with previous reports, demonstrating redundancy in the CUC family for cauline node patterning [11,12]. Very rarely, we observed that accessory axillary shoots, which are often formed at Arabidopsis cauline nodes between the axillary branch and its subtending leaf (Figure 2e), were fused with the stem of the axillary branch (Figure 8e), or that a branch was slightly fused with the base of its subtending cauline leaf. In contrast, in the rps10b-1 cuc3 double mutant, the frequency of obvious cauline node patterning defects was greatly enhanced. There was further loss of either the leaf or the axillary shoot, and increased fusion of organs, such that $76 \%$ of the double mutant nodes appeared abnormal (Table 3). The increase in the proportion of nodes showing abnormal leaf development (leaf absent or fused to the stem) in the double mutant, compared with rps10b-1 alone, was highly significant $\left(x^{2}=113.1, \mathrm{p}<0.0001\right)$. This was also the case when the proportions of nodes lacking an axillary shoot were compared $\left(\mathrm{x}^{2}=72.3, \mathrm{p}<0.0001\right)$.

Loss of CUC3 function has been reported mildly to affect embryonic shoot patterning, with cuc3 seedlings falling into two major classes: phenotypically normal, or showing one-sided cotyledon fusion. Occurrence of the severe cup-shaped phenotype caused by two-sided cotyledon fusion is rare $[10,11]$. This was also true for the cuc3 allele we used (Table 4). rps10b-1single mutant seedlings did not show cotyledon fusion but rarely, an extra cotyledon was present. Combining rps10b-1 and 


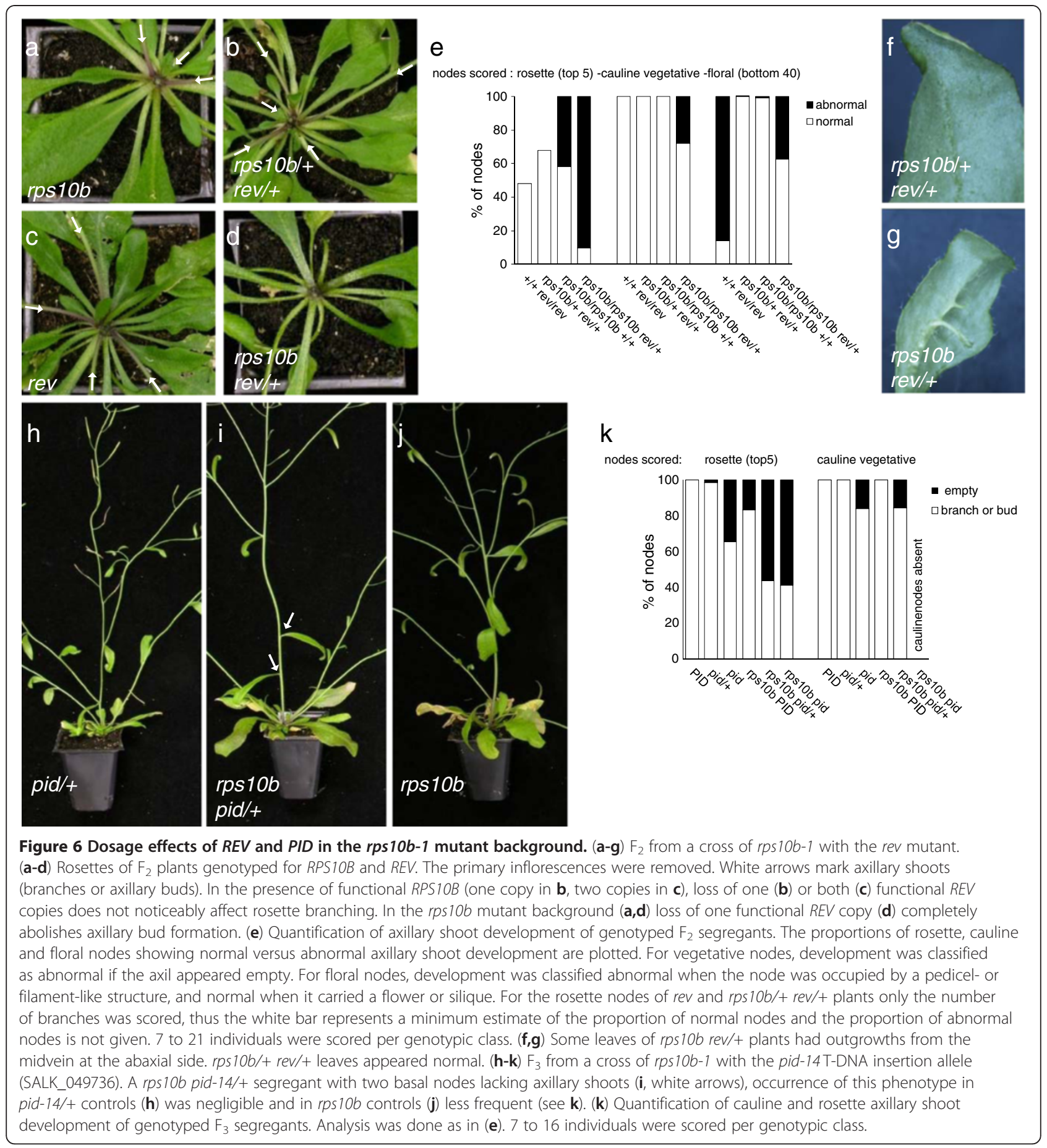

cuc3 doubled the proportion of seedlings showing cotyledon fusion $(13.9 \%$, compared to $7.7 \%$ for cuc3 alone, $\left.\mathrm{X}^{2}=6.77, \mathrm{p}=0.01\right)$. It also increased the proportion of seedlings showing severe, two-sided cotyledon fusion, but not significantly (Fisher's exact test, $\mathrm{p}=0.06$ ). Thus, the patterning of cotyledonary nodes appeared less sensitive to combined loss of RPS1OB and CUC3 function than the patterning of cauline nodes. Our observations suggest that CUC gene-mediated patterning depends on full RPS1OB function, but also that this dependence varies with the developmental context.

\section{Functional redundancy of RPS10B and RPS10C in the control of development}

Arabidopsis r-proteins are encoded by small gene families [78]. Two additional RPS10 family members, RPS10A 

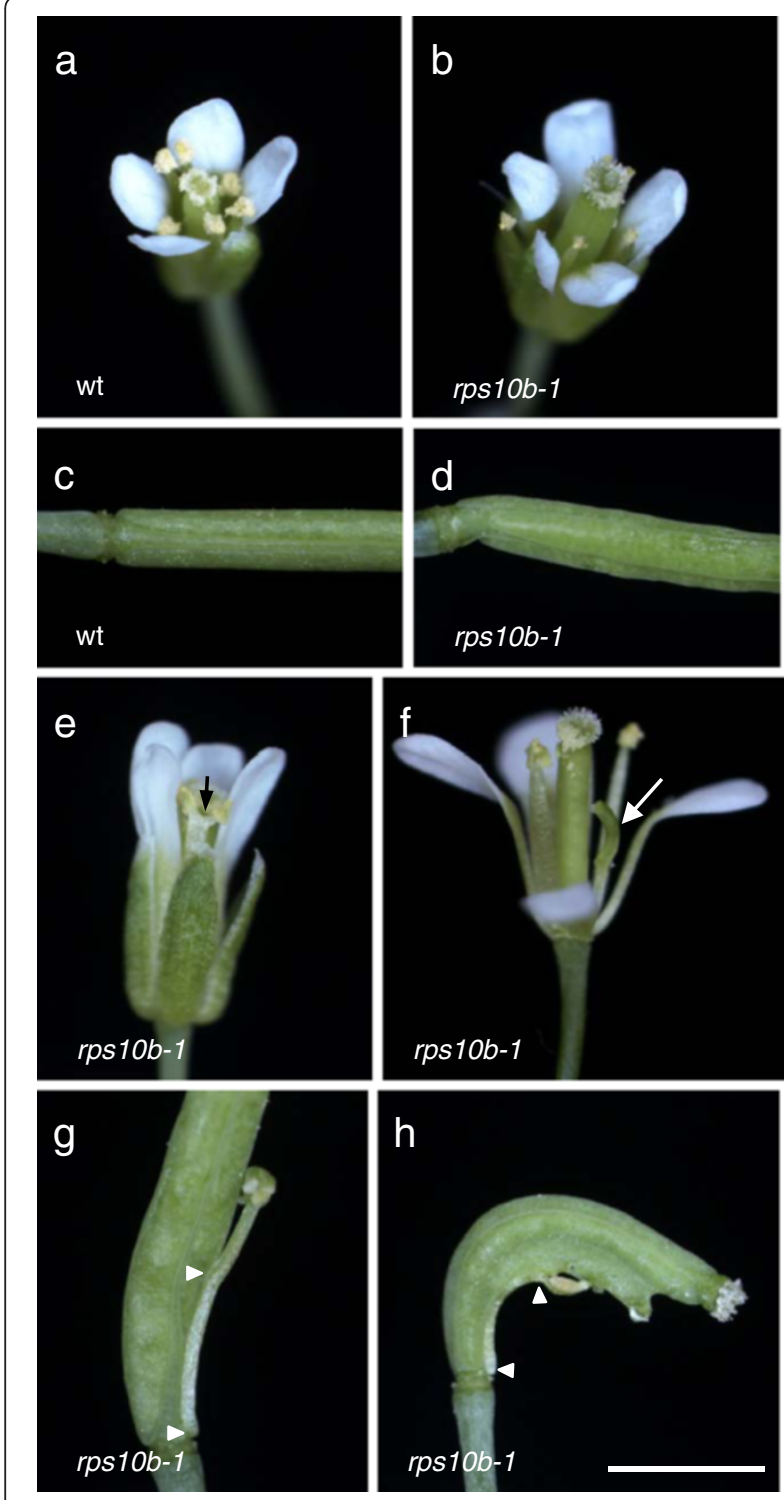

Figure 7 rps 10b-1 floral organ phenotypes. (a-d) Increased variation in floral organ number. Wild-type flower with four (a), rps 10b-1 flower with five petals (b). Developing siliques of wild type (c) with two carpels, of rps10b-1 (d) with three carpels. $(\mathbf{e}, \mathbf{g}, \mathbf{h})$ Defective organ separation. Fusion of two stamen filaments indicated by black arrow in (e). Fusion of stamen filaments to the gynoeceum marked by arrowheads in $(\mathbf{g}, \mathbf{h}) .(\mathbf{f}, \mathbf{g}, \mathbf{h})$ Mis-specification of organ identity. Stamens in (f, white arrow), (g) and (h) showing carpelloid features. Scale bar in (h) for (a-h): $2 \mathrm{~mm}$.

(At4g25740) and RPS10C (At5g52650), show 78\% and $74 \%$ amino acid identity with RPS10B. RT-PCR from cDNA produced from total RNA of different wild-type tissues showed that all three genes are transcribed and that their relative contributions to transcript level appear invariant for the tissues we analysed (Additional file 4: Figure S3). The AtProteome database [79] points to RPS10B as the most abundant protein isoform. To test for redundancy of protein function, we amplified a cDNA corresponding to the longest annotated protein version for each member, and expressed it under the control of the $R P S 10 B$ promoter in rps $10 b-1$ plants. As controls we used the wild type, rps10b-1, $\mathrm{T}_{1}$ plants from transformation of the mutant with the genomic RPS10B construct, and $T_{2}$ plants from transformation of the mutant with two JAtY TAC clones, only one of which contained the RPS10B genomic region. Complementation efficiency was scored by counting the stamens of 20 flowers from 8-13 individual plants per genotype or construct (Figure 9). The mean individual stamen numbers ranged between 5.7 and 6 for wild-type plants; but were below 5.4 for the mutant or transformants with the JAtY TAC clone that lacked RPS1OB. For the $\mathrm{T}_{2}$ transformed with the JAtY TAC containing RPS1OB, and for 9 out of $10 \mathrm{~T}_{1}$ transformed with the genomic RPS10B construct, stamen numbers ranged from 5.4 up to the maximum values obtained for wild-type plants. A mean stamen number lower than wild type but still above those of mutant plants may be explained by a lower dose of functional $R P S 10 B$ in some transformants than in wild type, as the majority of the JAtY $T_{2}$ and most of the $T_{1}$ are expected to contain one transgene copy. Of the three RPS10B promoter::cDNA fusions, $R P S 10 B:: B$ rescued most efficiently, however with a further reduction compared to the genomic construct, which could indicate a requirement to generate alternative transcripts, or for intronic or untranslated sequences for the proper control of RPS1OB gene expression. The RPS10B:: C construct complemented the stamen phenotype in about half of the $\mathrm{T}_{1}$; however, none of the RPS10B::A $\mathrm{T}_{1}$ was rescued. While the reason for the non-complementation by RPS10A is not clear, the rescue by the RPS10C cDNA argues against a specialised role of RPS10B within the S10e protein family.

\section{Discussion}

The RPS10 gene family

RPS10B belongs to the three-member Arabidopsis gene family encoding the eukaryote-specific protein S10e of the small cytoplasmic ribosomal subunit $[78,80]$. Like most of the r-proteins, S10e is essential for the biogenesis of its ribosomal subunit [81]. It is positioned at the "beak" of the small subunit, a structure that is formed from protein and rRNA in eukaryotes, but exclusively from rRNA in bacteria [82]. The role of S10e in translation is unknown. Crosslinking experiments indicate that S10e might participate in the interaction of the small subunit with eukaryotic initiation factor 3 , which functions in translation initiation [83,84].

The Arabidopsis rps10b-1 mutant allele is transcribed and can encode a truncated protein; its recessive inheritance is consistent with either reduced or abolished protein function. A knockout allele could not be obtained 
Table 2 Lateral organ numbers of wild-type and rps10b-1 flowers ${ }^{a}$

\begin{tabular}{|c|c|c|c|c|c|c|c|c|}
\hline \multirow[t]{2}{*}{ Genotype } & \multicolumn{2}{|l|}{ Sepal } & \multicolumn{2}{|l|}{ Petal } & \multicolumn{2}{|l|}{ Stamen } & \multicolumn{2}{|l|}{ Carpel } \\
\hline & Mean \pm SEM & Range & Mean \pm SEM & Range & Mean \pm SEM & Range & Mean \pm SEM & Range \\
\hline wild type & $4.00 \pm 0.00$ & 4 & $4.00 \pm 0.00$ & 4 & $5.92 \pm 0.03$ & $5-6$ & $2.00 \pm 0.00$ & 2 \\
\hline rps10b-1 & $4.00 \pm 0.05$ & $2-5$ & $4.22 \pm 0.06$ & $3-6$ & $4.17 \pm 0.09$ & $2-6$ & $2.13 \pm 0.04$ & $2-4$ \\
\hline
\end{tabular}

${ }^{\mathrm{a}}$ 98-100 flowers per genotype were examined under a dissecting microscope.

from T-DNA mutant collections. The fact that cDNAs of $R P S 10 B$ and RPS10C (driven by the RPS1OB promoter) rescued an rps10b-1 mutant phenotype to a similar extent, suggests that the RPS10B protein has not functionally diverged from other family members. We detected transcripts of all RPS10 family members in all tissues tested, with highest transcript levels in young, growing tissues, including axillary buds (Additional file 4: Figure S3).

\section{The specificity of ribosomal protein mutant phenotypes} An increasing collection of ribosomal protein mutants have been recovered from screens for developmental phenotypes in Arabidopsis, with substantial overlap in the suite of phenotypes conferred by these mutations.

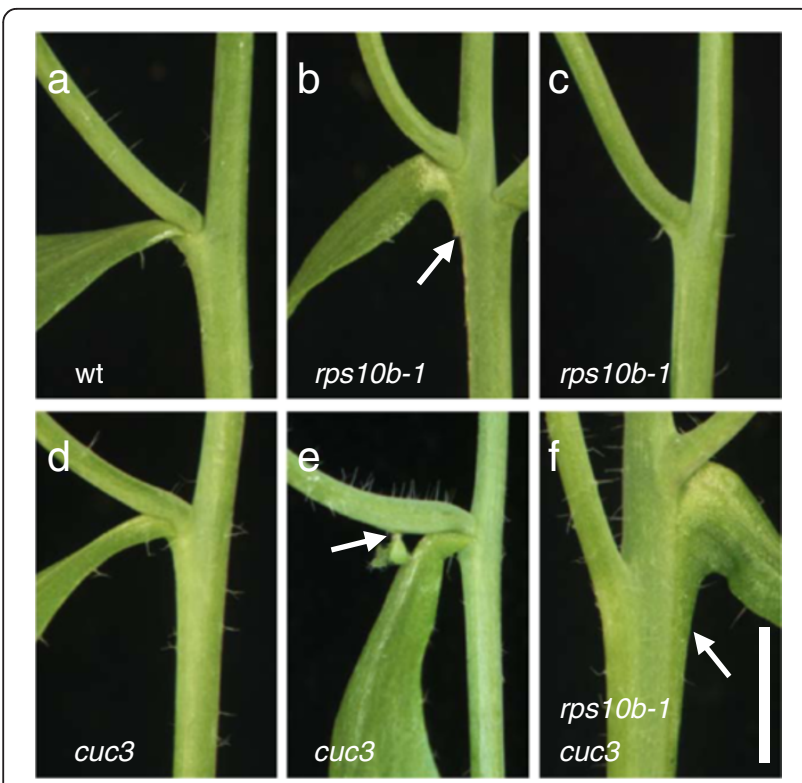

Figure 8 Genetic interaction between RPS1OB and CUC3 in organ separation. (a-f) Cauline vegetative nodes. cuc3 (GABI-KAT GK_302G09) nodes are phenotypically wild-type (compare a and d), with rare exceptions, as in e where a cuc3 accessory axillary bud (arrow) appeared to be fused with an axillary branch. rps10b-1 nodes occasionally show leaf-to-stem fusion (arrow in $\mathbf{b}$ ) or the cauline leaf is missing (c), in addition to the lack of the axillary bud which was shown in Figure 2f,g. The upper of the two rps10b-1 cuc3 double mutant nodes in $\mathbf{f}$ shows leaf-to-stem fusion (arrow). The bottom node lacks the cauline leaf and the bottom of the axillary branch may be fused with the primary inflorescence.Scale bar in (f) for (a-f) $5 \mathrm{~mm}$.
The phenotypes include altered leaf shape (the first leaves are narrow and pointed) and the ability to enhance the phenotype of mutations that affect leaf adaxial identity, for example asymmetric leaves1 (as1) or as 2 [85-91]. However, these r-protein mutations differ substantially in their effects on plant growth, which could reflect variation in the degree of genetic redundancy. In rps10b-1, expression of the pointed first leaf phenotype was mild. Leaf polarity was affected in double mutant combination with rev (Figures 6,7) and we confirmed that this was also the case with as1 (Additional file 5: Figure S4). Although we observed weak effects on growth rate, for example in axillary buds on isolated nodal segments, the shoot or organ size of mature plants was not noticeably reduced, arguing against a general growth defect. The basis of the developmental defects of r-protein mutants is unclear. Two possibilities seem likely.

First, defective ribosomes may trigger specific developmental defects through their participation in surveillance mechanisms at cell cycle checkpoints. For example in humans, redundancy of r-proteins is less common, and haploinsufficiency of S10e and several other proteins of the large or small ribosomal subunit cause DiamondBlackfan anemia, a syndrome of specific developmental defects including the failure of red blood cell progenitors $[92,93]$. According to current understanding of the disease, these mutations perturb ribosome biogenesis via an imbalance in ribosome constituent stoichiometry. This is likely to increase the level of unincorporated r-proteins, several of which can bind and inactivate a ubiquitin ligase which targets the p53 tumor suppressor protein $[94,95]$, and its resulting stabilization triggers cell cycle arrest in red blood cell progenitors. It may be that this surveillance mechanism operates in certain cell types only, for example cells that proliferate very rapidly $[96,97]$, which could explain the developmental specificity of the phenotype. It is not known whether similar surveillance systems operate in plants.

Second, ribosome insufficiency, the production of disfunctional ribosomes, or the lack of ribosomes containing a specific $r$-protein variant could affect the production of specific proteins more than others. For example developmental patterning or cell cycle genes might crucially depend on particularly high translation rates or on a specialized ribosome variant. An interesting case here is the 
Table 3 cuc $^{\mathrm{a}}$ strongly enhances the effect of rps10b-1 on the development of cauline vegetative nodes

\begin{tabular}{|c|c|c|c|c|c|c|c|}
\hline \multirow[t]{3}{*}{ Genotype } & \multicolumn{3}{|c|}{ Axillary shoot score } & \multicolumn{3}{|c|}{ Leaf score } & \multirow[t]{3}{*}{ Nodes scored } \\
\hline & \multicolumn{3}{|c|}{$\%$ of cauline nodes } & \multicolumn{3}{|c|}{$\%$ of cauline nodes } & \\
\hline & normal & $\begin{array}{l}\text { branch-stem } \\
\text { fusion }\end{array}$ & $\begin{array}{l}\text { without } \\
\text { axillary bud }\end{array}$ & normal & $\begin{array}{l}\text { leaf-stem } \\
\text { fusion }\end{array}$ & $\begin{array}{l}\text { without } \\
\text { leaf }\end{array}$ & \\
\hline wild type & 100.0 & 0.0 & 0.0 & 99.4 & 0.6 & 0.0 & 171 \\
\hline rps10b-1 & 95.5 & 0.0 & 4.5 & 96.3 & 0.8 & 2.9 & 244 \\
\hline cuc3 & 99.2 & 0.8 & 0.0 & 100.0 & 0.0 & 0.0 & 121 \\
\hline rps10b-1 cuc3 & 57.6 & 4.6 & 37.7 & 51.7 & 37.7 & 10.6 & 151 \\
\hline
\end{tabular}

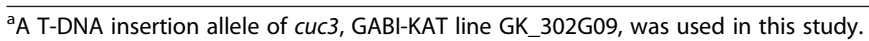

${ }^{\mathrm{b}}$ The cauline vegetative nodes along the primary inflorescence of 38-40 plants per genotype were scored by the naked eye.

Aux/IAA transcriptional repressors, which are central to auxin-regulated gene expression. Some members of this protein family have extremely short half-lives, in the order of 5 minutes [98], and are maintained at steady state level in cells with a particular auxin concentration. Upon auxin addition, their half-lives are further reduced [64,99], resulting in their depletion and hence the up-regulation of transcription by a sub-family of ARFs. Because of the need for continuous replenishment of these proteins, it is possible that developmental events dependent on dynamic changes in auxin signaling are particularly sensitive to inefficient ribosomes. Alternatively, the consequences of reduced or altered ribosome function might be enhanced by specific features of the mRNA encoding a protein, for example by the presence of upstream ORFs, which require translation re-initiation. This is the case for the mRNAs of several ARF transcription factors, including ARF3 (ETTIN) and ARF5 (MONOPTEROS, MP), and was proposed to cause arf-like developmental phenotypes of the r-protein mutant short valve1 (rpl24b) [100]. Another ribosome-dependent process, which might potentially be affected is miRNA-directed translational regulation [101,102]. Many of the genes involved in meristem patterning and adaxial identity are regulated by small RNAs $[103,104]$.

The work presented here is suggestive of this second set of possibilities, because many of the effects we observe are indicative of a general lack of robustness of the adaxial patterning system, with the rps10b-1 mutation rendering the system sensitive to the dosage of other important regulatory components.

\section{RPS10B and shoot meristem function}

Despite the intuitive lack of specificity expected from a ribosomal protein mutation, it is clear that mutation of RPS1OB causes a syndrome of phenotypes that can be attributed to patterning events at the shoot apical meristem, and particularly to the establishment of boundaries between the meristem and the leaf, and to a lesser extent, within the leaf.

rps10b-1 suppresses excessive shoot branching in the max2-1 mutant background. A reduced ability to initiate or maintain axillary shoot meristems is a major cause of this suppression. The axillary shoot defects of rps10b-1 were enhanced in double mutant combination with axr 1, fhy3, rev, and pid, and were sensitive to reductions in the dose of REV and PID. Moreover, maintenance of the primary shoot apical meristem was partially affected in combination with axr1 and fhy3; a phenotype not observed in the single mutants. Finally, rps10b-1 enhanced the floral meristem defects of rev and pid. This indicates a general role of RPS1OB in shoot meristem function. In addition, the rps10b-1 rev double mutant phenotype revealed that $R P S 10 B$ is involved in leaf polarity, like many other r-protein genes.

While axillary meristem defects have not yet been reported for $\mathrm{r}$-protein gene single mutants (perhaps because they are relatively weak), introgression of piggy 1 (rpl10ab) into a rev mutant, stv1 (rpl24b) into an arf3 mutant and rpl4d into an as1 mutant background resulted in striking axillary and/or floral meristem defects $[88,100,105]$. Formation of the embryonic shoot meristem; and shoot meristem, vascular and leaf patterning

Table 4 rps10b-1 weakly enhances cuc $3^{\mathrm{a}}$ seedling phenotypes

\begin{tabular}{llllllr}
\hline Genotype & $\begin{array}{l}\text { Seedlings } \\
\text { scored }\end{array}$ & Normal & 3 cotyledons & Cotyledons fused & \% Abnormal \\
\cline { 5 - 6 } & 317 & 316 & 0 & One-sided & Two-sided & 0.3 \\
\hline wild type & 300 & 299 & 1 & 0 & 0 & 0.3 \\
rps10b-1 & 353 & 326 & 0 & 26 & 1 & 7.7 \\
cuc3 & 310 & 267 & 0 & 37 & 6 & 13.9 \\
rps10b-1 cuc3 & & &
\end{tabular}

${ }^{\mathrm{a}} \mathrm{A}$ T-DNA insertion allele of cuc3, GABI-KAT line GK_302G09, was used in this study. 


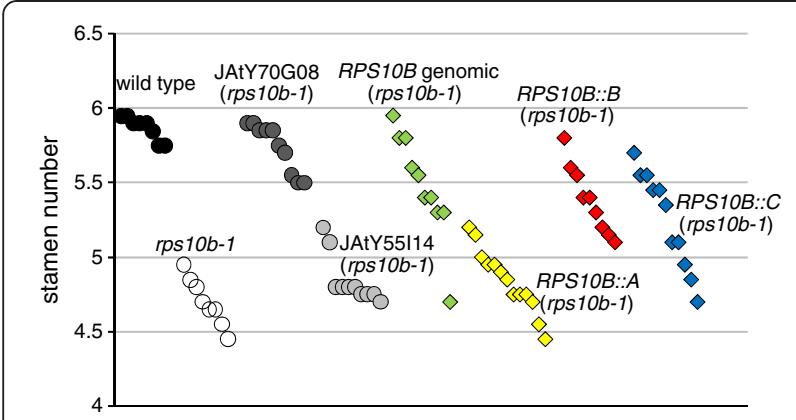

Figure 9 Assessing functional redundancy of RPS10 proteins. RPS1OB promoter::RPS10CDNA fusions were constructed for the RPS10 family members $A, B$ and $C$ and transformed into rps 10b-1. The $T_{1}$ was scored for rescue of reduced stamen number, an rps10b-1 developmental phenotype. Controls: wild type, rps 106-1, transgenic $\mathrm{T}_{2}$ plants from transformation of rps 10b-1 with JAtY TAC clone 70 G08 which spanned, and clone 55114 which lacked the RPS10B genomic region; and $T_{1}$ plants from the transformation of rps 10b-1 with a genomic RPS1OB clone. Each symbol represents the mean stamen number of 20 flowers from the primary inflorescence of one individual plant.

crucially depend on an interaction between HDZIPIII and $K A N$ genes $[2,19,106]$. Furthermore, axillary and embryonic shoot meristem formation are similar in many respects and likely to share the HDZIPIII /KAN patterning mechanism. With respect to leaf patterning, r-protein genes were found to promote genetically the adaxialising role of the HDZIPIII genes, and to antagonise the action of the abaxialising KAN genes [105,107]. RPS10B genetically promoted the action of $R E V$ both in shoot meristem function and leaf polarity. Interestingly, axillary meristem formation appeared more sensitive to halving the $R E V$ dose in the rps10b-1 background, than did leaf polarity. This supports the notion that RPS10B acts at least partly via meristem establishment itself, and not only via the specification of leaf adaxial fate, which is a prerequisite for axillary meristem initiation in Arabidopsis $[5,7,8,16]$. Despite the strong genetic interactions between r-protein genes and the HDZIPIII/KAN pathway, further analysis did not implicate any of the ad- or abaxial polarity genes examined as direct targets of ribosomal regulation $[88,91,105,107]$.

The rps10b-1 mutant displayed other shoot meristemrelated phenotypes that were not enhanced in combination with rev. Cauline nodes lacked a leaf, or the leaf was rudimentary. Sometimes, the cauline leaf margin was fused to the stem. Floral organ numbers were more variable than in the wild type and, organ fusion within and between whorls occurred. Such phenotypes indicate misregulated organ separation. Some rps10b-1 phenotypes resemble loss of function, while others resemble gain of function phenotypes described for the three partially redundant CUC genes [9-12,108-110]. Furthermore, combining rps10b-1 and cuc3 enhanced organ separation defects which were rare in the single mutants, most dramatically at cauline nodes. In the r-protein mutant rpl27ac-1d, CUC2 was mislocalised during embryonic shoot meristem formation [91]. Interestingly, the leaf polarity regulators $A S 1$ and $A S 2$ have been implicated in $C U C$ gene regulation and organ boundary formation [111-113]. Conversely, mutant phenotypes suggest a role for $C U C$ genes in leaf polarity [11]. This suggests that the well-known ribosomal regulation of leaf polarity, and the organ boundary role we describe here for RPS1OB could have a shared molecular basis.

\section{RPS10B and auxin}

A common feature of many of the developmental events described above is their dependence on, or interaction with auxin and its directed transport. The formation of both the leaf-meristem boundary and the leaf abaxial-adaxial boundary involve the specific and dynamic reorientation of auxin transport paths and hence auxin distribution patterns [14]. Consistent with the importance of auxin in these events, the general reduction in the robustness of the patterning of these boundaries in the rps10b-1 mutant is associated with a range of auxin-related phenotypes.

First, mutations affecting auxin signalling or transport enhanced some of these defects. The auxin signalling mutation axr1-3, which does not affect axillary shoot formation in a wild-type background [66], enhanced axillary bud loss in combination with rps10b-1. In addition, a novel phenotype of primary inflorescence meristem arrest was displayed by some axr1-3 rps10b-1 double mutant plants. The effects of reduced or abolished function of the auxin transport regulator PID on lateral organ formation were enhanced in the rps10b-1 mutant background. The effect of both these auxin-related mutations may be to interfere with $A R F$-regulated developmental programmes either globally $(\operatorname{axr} 1)$ or through altered auxin distribution (pid). Mutation of the transcriptional activator $F H Y 3$, another max2 branching suppressor from our screen, very strongly enhanced axillary meristem failure when combined with rps10b-1, and also caused inflorescence meristem arrest. We hypothesise that $F H Y 3$ also regulates branching via auxin signalling or homeostasis [73].

Second, the amp1-1 mutation suppressed the axillary meristem failure of rps10b-1 in the double mutant. Although the molecular function of AMP1 is not known, loss-of-function mutant phenotypes suggest that it restricts shoot meristematic growth $[70,114]$. Increased levels of cytokinins have been detected in amp1 plants $[67,68]$, which might cause their increased meristematic stem cell activity [115]. Interestingly, a link between $A M P 1$ and $A R F$-mediated auxin signaling has recently been proposed. amp1 suppresses the effect of loss of ARF5 (MP) in embryonic shoot meristem development 
and vascularisation, indicating that one important activity of $M P$ might be to antagonise $A M P 1$ [71]. In this way, auxin signalling in the shoot meristem could sustain the stem cell pool required for future lateral organ formation. The genetic interactions of rps10b with axr1, pid, and amp1 are consistent with RPS1OB supporting stem cell production indirectly by maintaining $A R F$ mediated auxin signalling.

\section{RPS10B and axillary bud outgrowth}

In addition to axillary meristem specification defects, which likely underlie the poor axillary shoot formation phenotype of the rps10b-1 mutant, we also detected defects in axillary meristem activity, which may contribute to the suppression of shoot branching in $\max 2$. Because of the effects on axillary bud formation, it was difficult to ascertain the effect of rps $10 \mathrm{~b}$ on bud outgrowth in intact plants. Therefore, we used excised cauline nodes, which were selected for approximately equal bud size at the start of the experiment. Except for one specific situation, which is discussed below, the effect of rps $10 b$ on bud outgrowth rate was surprisingly small, given the transcriptional evidence for high r-protein synthesis in active buds $[25,26]$. This could indicate that loss of $R P S 10 B$ was compensated by functional family members. Mechanisms that ensure that ribosomal components are produced in stochiometric amounts are better studied in other organisms, but they are likely to operate in plants as well $[116,117]$. We detected at most a slight upregulation of RPS10A or $C$ transcripts in rps $10 b$ by semi-quantitative RT-PCR (Figure 1f). However, the example of the Arabidopsis rpl4a and rpl4d mutants shows that compensation at the protein level can occur in the absence of detectable compensation at the transcript level [118].

The F-box protein MAX2 is required for normal strigolactone responsiveness, and is thought to act in an E3 ubiquitin ligase, selecting unknown protein targets for degradation $[119,120]$. Strigolactones are negative regulators of PIN protein levels, and of polar auxin transport in the vasculature [55]. Recent studies with excised axillary buds, to which a synthetic strigolactone was applied via the basal internode yielded two interesting observations. First, the ability of strigolactone to inhibit single excised buds required apical auxin; second, if buds on two consecutive nodes were excised, basal strigolactone enhanced the growth differential or competition between them, rather than inhibiting both $[55,121]$. This fits with a model of bud regulation via auxin transport canalisation, where bud activation requires the export of auxin via a shared auxin transport route in the stem, and strigolactones inhibit this process by restricting PIN protein accumulation [45]. Consistent with this, axillary buds of strigolactone mutants, including $\max 2$, are moderately resistant to apically applied auxin [55,60]. Interestingly, we found that the growth-inhibiting effect of rps10b on auxin-treated $\max 2$ buds was much stronger than for other genotypes and treatment combinations, such that bud outgrowth kinetics of the auxin-treated double mutant were restored to wild-type. This could indicate that rps $10 b$ specifically suppresses a downstream effect of the $\max 2$ mutation in bud outgrowth. This effect might be auxin-related, as rps $10 b$ specifically suppressed auxin responsive gene expression, as reported by DR5::GUS activity, in the shoot axis of rps10b max2, while it did not have this effect in the MAX2 background. A mode of action different from strigolactone / MAX2 is suggested by the fact that rps10b did not antagonise the effect of $\max 2$ on stem polar auxin transport; and the fact that rps10b did not restore the altered shoot vascular architecture of max2 back to wild type (compare sections of older plants in Figure $3 g-j)$. The vasculature of $\max 2$ stems shows increased activity of the PIN1::PIN1-GFP reporter $[55,60]$. In a recent evaluation of the vascular role of the HDZIPIII and KAN genes, both contributed to focused and canalised auxin movement during vascular differentiation; it was proposed that $K A N$ genes act by downregulating PIN activity, and that HDZIPIIIs promote the differentiation of xylem tissues, including the auxin-conducting xylem parenchyma [42]. A relatively subtle change in the HDZIPIII / KAN activity balance characteristic for the r-protein mutants, with lowered HD/ZIPIII or increased KAN activity, might not be critical for bud auxin export and activation in wild type, but might prevent buds of $\max 2$ from activating when there is a higher auxin load in the main stem.

\section{Conclusions}

Our analysis of RPS10B function suggests a role in patterning and in boundary establishment at the shoot apex, processes that are intimately connected with dynamic regulation of auxin flows. Furthermore, RPS10B is required to sustain the outgrowth of $\max 2$ axillary buds in the presence of auxin, while it is largely dispensable for bud outgrowth otherwise. Regulation of development is not likely to be a specialised role of RPS10B within the S10e protein family. However rps10b-1 and other r-protein mutants highlight the importance of ribosomal function for normal development. Combined with advances in the study of ribosomal activities [122], they might in the future help us to understand how plant ribosomal biogenesis and translation are controlled and integrated with development and growth.

\section{Methods}

\section{Plants and growth conditions}

Ecotype Col-0 was used as the wild-type control, and unless stated otherwise mutant lines were in this genetic 
background. The following lines were described previously: amp1-1 [67,69], axr1-3 [65,123], brc1-2 and brc2-1 (SALK_091920 and SALK_023116 [28]), fhy3-12 [73], $\max 2-1$ [54], $\max 4-1[62]$ and pid-14 [34,76]. Two lines obtained from T-DNA mutant collections were characterised by sequencing from both T-DNA borders: SALK_102345, an insertion in the last exon of $R E V$ (At5g60690) upstream of the termination codon, and GABI-KAT line GK_302G09, an insertion affecting the second exon of CUC3 (At1g76420). Multiple mutants which we constructed were confirmed by genotyping, using wild-type and T-DNA allele-specific PCR for insertional alleles, and CAPS [124] or dCAPS [125] markers for point mutation alleles; except for max4-1, where homozygosity was confirmed by testing progeny for uniform BASTA-resistance. As REV and RPS1OB are linked, a reduced frequency of double mutant individuals was expected in the $\mathrm{F}_{2}$ of the rps $10 \mathrm{~b} \times \mathrm{rev}$ cross. Therefore, 36 rps10b-1 homozygous $\mathrm{F}_{2}$ were selected based on their seedling leaf phenotype, genotyped for RPS1OB and REV, and their leaf and lateral shoot development was observed. For the cross rps10b x pid-14, genotyping was used in the $\mathrm{F}_{2}$ to identify rps10b-1 pid-14/+ individuals expected to segregate the double mutant in the $\mathrm{F}_{3}$, with $R P S 10 B$ pid-14/+ individuals used as controls. About $40 \mathrm{~F}_{3}$ progeny each were then genotyped and phenotyped.

Arabidopsis seeds were sown onto Levington F2 compost pretreated with systemic insecticide (Intercept 70WG, Everris Limited, Ipswich, UK). Trays were chilled at $4^{\circ} \mathrm{C}$ for 3 days and then incubated in a greenhouse with 16-h supplemental lighting. These conditions were used for all soil-grown plants except for the hypocotyls examined by histology (Figure 3). These were from 14day-old plants grown in continuous low light $(40 \mu$ moles $\mathrm{m}^{-2} \mathrm{sec}^{-1}$ from white fluorescent tubes, $21^{\circ} \mathrm{C}$ ) and from 60-day-old plants grown in short (8-h) photoperiods $\left(160 \mu\right.$ moles $\mathrm{m}^{-2} \mathrm{sec}^{-1}$ from fluorescent white tubes, $21^{\circ} \mathrm{C}$ day $/ 17^{\circ} \mathrm{C}$ night temperature). Except for the mutant screen described below, individual plants were grown at a density of 1 per $16 \mathrm{~cm}^{2}$ in trays consisting of $40 \times 16 \mathrm{~cm}^{2}$ compartments.

\section{Identification of RPS10B as a max2-1 suppressor}

max2-1 seeds were mutagenised with $0.3 \%$ ethyl methanesulfonate. 18000 seeds from the resulting $\mathrm{M}_{2}$ generation were sown at densities of one plant per 3 or $5 \mathrm{~cm}^{2}$ and screened for reduced rosette branching at maturity. One of the suppressor mutations isolated, 6-7, was recessive and segregated independently from $\max 2-1$ after backcrossing to Columbia wild-type. The suppressor locus was mapped to a $126-\mathrm{kbp}$ interval on Chromosome 5 using about 1600 mutant individuals from the $F_{2}$ of a cross between Ler plants and the 6-7 mutant in the
MAX2 background. End-sequenced TAC clones from the Arabidopsis wild-type Columbia genomic JAtY library in pYLTAC17 [57] with inserts spanning the mapping interval were obtained from the John Innes Genome Laboratory, and transformed into Agrobacterium strain GV3101 for floral dipping of 6-7 MAX2. This was done according to Clough and Bent [126], except that the infiltration medium contained glucose instead of sucrose. $\mathrm{T}_{1}$ selected for BASTA-resistance under sterile conditions were further cultivated on soil. Their phenotypic rescue was scored; and they were genotyped to confirm the presence of the left and right vector genomic insert borders specific to the TAC clone.

\section{RNA isolation, RT-PCR, cloning}

Total RNA was extracted using the RNeasy plant miniprep kit with on-column DNaseI digestion (Qiagen, Hilden, Germany) from about $100 \mathrm{mg}$ tissue powder, obtained from 10 pooled $1-\mathrm{cm}$ primary inflorescence stem base segments per genotype, from bolting plants of about $25 \mathrm{~cm}$ height. cDNA synthesis was performed from $1 \mu \mathrm{g}$ total RNA in a total volume of $10 \mu \mathrm{l}$ with SuperscriptII (Invitrogen, Life Technologies, Carlsbad, CA) and oligo-dT primer. After diluting each sample by adding $70 \mu \mathrm{l}$ of water, $2 \mu \mathrm{l}$ were used in $50 \mu \mathrm{l}$ semiquantitative PCR reactions with 26 cycles, unless stated otherwise. Gene-specific RPS10A-, RPS10B- and RPS10C primer pairs were used. RT-PCR for ACTIN2 (At3g18780) was used as RNA input control. Primer sequences are listed in Table 5.

A genomic RPS10B construct was produced by amplifying a $3.5 \mathrm{~kb}$ fragment spanning the RPS10B genomic region from Columbia wild-type genomic DNA with primers RPS10BgenomicF and RPS10BgenomicR (Table 5). This was digested with SpeI and HindIII and cloned into binary vector pCAMBIA2300 (http://www.cambia.org) opened with XbaI and HindIII for plant transformation.

To express RPS10A, RPS10B, RPS10C cDNAs under the $R P S 10 B$ promoter, $R P S 10 B$ promoter region was amplified from Columbia wild-type genomic DNA, and the RPS10A (At4g25740.1), RPS10B (At5g41520.1) and RPS10C (At5g52650.1) coding regions were amplified from Columbia wild-type cDNA using the primers specified in Table 5. The three forward primers for the RPS10 coding regions introduced an overlap with the RPS1OB promoter amplicon, which was then fused upstream of each cDNA by overlap extension in a second round of polymerase chain reaction. Furthermore, the primers introduced a BamHI site followed by a NotI site just upstream of the promoter and an XbaI site just downstream of the termination codon. The products were digested with $\mathrm{BamHI}$ and $\mathrm{XbaI}$ and ligated into the cloning vector pART7 [127] opened with the same enzymes. Inserts were confirmed by sequencing. From these plasmids, NotI 
Table 5 Primers used in this study

\begin{tabular}{|c|c|}
\hline Primer name & Sequence $5^{\prime} \rightarrow 3^{\prime}$ \\
\hline \multicolumn{2}{|c|}{ RPS10B genomic construct } \\
\hline RPS10Bgenomic-F & AAACTAGTAACCGAGTAAACGGGATGATTAGG \\
\hline RPS10Bgenomic-R & AAAAAAAGCTTAGCTCCTCAACATTCAACTCCTTC \\
\hline \multicolumn{2}{|c|}{ RPS10B promoter::RPS10A, RPS10B and RPS10C cDNA constructs } \\
\hline RPS10Bpro-F & $\begin{array}{l}\text { GGATCC GCGGCCGCTGAATAAGTAACATCAAACTC- } \\
\text { CAGCTA }\end{array}$ \\
\hline RPS10Bpro-R & ATCATGATTGCGATGAGATTGAAGAAGGA \\
\hline RPS10ACDNA-F & $\begin{array}{l}\text { CTTCAATCTCATCGCAATCATGATTATCTCAGAGAAC- } \\
\text { AATCGCAG }\end{array}$ \\
\hline RPS10ACDNA-R & AATCTAGATCAAGGGAACCCTGAACCAGATGGTGCT \\
\hline RPS10BCDNA-F & $\begin{array}{l}\text { CTTCAATCTCATCGCAATCATGATCATATCAGAGACT- } \\
\text { AACCGCCGT }\end{array}$ \\
\hline RPS10BCDNA-R & AATCTAGA TCAAGGAAGATCAGATCCAGCAGCA \\
\hline RPS10CCDNA-F & $\begin{array}{l}\text { CTTCAATCTCATCGCAATCATGATTATCTCAGAGGCT- } \\
\text { AACCGCAAA }\end{array}$ \\
\hline RPS10CcDNA-R & AATCTAGATCAAGGCAAACCTGAACCAGATGGTGCA \\
\hline \multicolumn{2}{|l|}{ RT-PCR } \\
\hline RPS10A-RT-F & AGATTTGGTGACCGTGATGGATAC \\
\hline RPS10A-RT-R & CCTTCCATCGTCGCAATATGAC \\
\hline RPS10B-RT-F & AGGTTTGGTGACAGAGATGGATAC \\
\hline RPS10B-RT-R & AGACCAAAAAGAAACAAGAAAGTCC \\
\hline RPS10C-RT-F & GTTGGTGACCGTGATGGGTAC \\
\hline RPS10C-RT-R & AACTCCTCCATGGTCTTACTGTC \\
\hline CCD7-F & CCGAGTCAAGCTTAATCCAATAG \\
\hline CCD7-R & ATTGCAGTTTCCGGTAGAGTCCAA \\
\hline CCD8-F & CATCGGCGATCAACAAATAA \\
\hline CCD8-R & GTTAAACCAAATCCGGTATC \\
\hline Ubiquitin5-F & AACCCTTGAGGTTGAATCATC \\
\hline Ubiquitin5-R & GTCCTTCTTTCTGGTAAACGT \\
\hline Actin2-RT-F & TTACCCGATGGGCAAGTCA \\
\hline Actin2-AT-Rev & CACCACTGAGCACAATGTTAC \\
\hline
\end{tabular}

releases a fragment consisting of the $R P S 10 B$ promoter, the $R P S 10 A, B$ or $C$ coding region and the plasmid-encoded octopine synthase gene terminator, which was transferred into a NotI-digested derivative of the plant transformation vector pART27 [127] which confers BASTAresistance in plants. Confirmed constructs were shuttled into Agrobacterium strain GV3101 and used for plant transformation [126].

\section{Auxin physiology and transport, histology of hypocotyl sections stained for DR5::GUS activity}

Axillary bud outgrowth assays were performed with cauline nodes excised from the primary inflorescence of plants grown in sterile conditions, as described [59]. $2-{ }^{14} \mathrm{C}$-indoleacetic acid transport assays were conducted with $1.5-\mathrm{cm}$ stem segments from the basal internode of the primary inflorescence of 6-week old soil-grown plants $[55,60]$.

$2 \mathrm{~mm}$ of apical hypocotyl tissue and the cotyledonary node of 14 day-old seedlings germinated under continuous illumination and 2-mm segments from the thickened hypocotyls of 60-day-old short-day-grown plants were stained for $\beta$-glucuronidase (GUS) activity at $37^{\circ} \mathrm{C}$ overnight, fixed for $5 \mathrm{~h}$, and embedded in Technovit (Heraeus Kulzer, Hanau, Germany); $10 \mu \mathrm{m}$ transverse sections were prepared, mounted to slides, counterstained with ruthenium red, and permanently mounted as described [119].

\section{Additional files}

Additional file 1: Table S1. rps10b-1 complementation analysis.

Additional file 2: Figure S1. rps10b-1 does not suppress strigolactone insensitivity of max2-1 hypocotyls. Relative hypocotyl lengths of lightgrown wild-type, rps10b-1, max2-1 and rps10b-1 max2-1 seedlings after

7 days of growth on vertical sterile agar plates without

or with the synthetic strigolactone GR24. Mean hypocotyl lengths

( $n=19-28$ ), were normalized to the mean length on control medium for each genotype. Error bars represent the standard error of the ratios. Sterile growth conditions and preparation of GR24 according to [55] except that sucrose was omitted from the growth medium.

Additional file 3: Figure S2. rps10b-1 does not suppress upregulation of the genes encoding strigolactone biosynthetic enzymes CCD7 (CAROTENOID CLEAVAGE DIOXYGENASE7) and CCD8 in max2-1 mutant inflorescence stems. RT-PCR analysis of the transcript levels of CCD7 and CCD8 in total RNA prepared from basal primary inflorescence stem segments. RT-PCR for UBIQUITIN5 (UBQ5) was used as RNA normalization control.

Additional file 4: Figure S3. Widespread expression of RPS1OA, RPS1OB and RPS1OC and lack of tissue-specific variation in their relative contributions to transcript level. RT-PCR analysis of the transcript levels of RPS10A, RPS10B and RPS10C in total RNA prepared from different Columbia wild-type Arabidopsis tissues was carried out as described [119]. Gene-specific amplification was ensured by reverse priming to divergent 3'-untranslated sequences. RT-PCR for ACTIN2 was used as RNA normalization control.

Additional file 5: Figure S4. rps10b-1 enhances leaf polarity defects of the asymmetric leaves 1 (as1) mutant. The as 1-1 allele in the Col-1 background (NASC stock N3374) was used in this experiment. Rosette centres of wild type (a), rps10b-1 (b) and as 1 (c) controls and of putative double mutant rps10b-1 as $1 \mathrm{~F}_{2}$ segregants from a cross of the single mutants (d, e). While the oldest leaves of these plants appeared as 1-like, younger leaves were trumpet-shaped, or their leaf lamina was strongly reduced (arrows). These segregants bolted normally and produced flowers and seeds. Scale bars: $5 \mathrm{~mm}$ in (d) for (a-d) and $1 \mathrm{~mm}$ in (e).

\section{Competing interests}

The authors declare no competing interests.

\section{Authors' contributions}

PS isolated the mutant, performed the genetic and phenotypic characterisation, and made the RPS10 constructs. JPL, SLK and SW mapped the mutant gene. JPL and PS performed mutant rescue experiments. Excised node assays were carried out by SW. PS and OL wrote the manuscript. All authors read and approved the final manuscript.

\section{Acknowledgements}

Mohamed Asrih initially mapped 6-7 to Chromosome 5. We thank Pilar Cubas, Remko Offringa, Tobias Sieberer and the Nottingham Arabidopsis Stock Centre for seeds, and the John Innes Genome Laboratory for providing 
JAtY TAC clones. The York University horticultural team provided excellent plant care. This work was funded by grants from the BBSRC and the Gatsby foundation. JPL was supported by a scholarship from the State Scholarship Fund of P. R. China, with thanks to the China Scholarship Council (CSC).

\section{Author details}

'Department of Biology, University of York, Wentworth Way, York YO10 5DD, UK. ${ }^{2}$ Present Address: College of Agronomy, Hainan University, No. 58 Renmin Avenue, Haikou, Hainan Province 570228, People's Republic of China. ${ }^{3}$ Present Address: Sainsbury Laboratory, Cambridge University, Bateman Street, Cambridge CB2 1LR, UK. ${ }^{4}$ Present Address: Department of Biology, Centre for Novel Agricultural Products, University of York, Wentworth Way, York YO10 5DD, UK

Received: 15 May 2012 Accepted: 11 August 2012

Published: 10 September 2012

\section{References}

1. Long J, Barton MK: Initiation of axillary and floral meristems in Arabidopsis. Dev Biol 2000, 218:341-353.

2. Barton MK: Twenty years on: the inner workings of the shoot apical meristem, a developmental dynamo. Dev Biol 2010, 341:95-113.

3. Keller T, Abbott J, Moritz T, Doerner P: Arabidopsis REGULATOR OF AXILLARY MERISTEMS1 controls a leaf axil stem cell niche and modulates vegetative development. Plant Cell 2006, 18:598-611.

4. Müller D, Schmitz G, Theres K: Blind homologous R2R3 Myb genes control the pattern of lateral meristem initiation in Arabidopsis. Plant Cell 2006, 18:586-597.

5. Talbert PB, Adler HT, Parks DW, Comai L: The REVOLUTA gene is necessary for apical meristem development and for limiting cell divisions in the leaves and stems of Arabidopsis thaliana. Development 1995, 121:2723-2735.

6. Otsuga D, DeGuzman B, Prigge MJ, Drews GN, Clark SE: REVOLUTA regulates meristem initiation at lateral positions. Plant J 2001, 25:223-236.

7. Emery JF, Floyd SK, Alvarez J, Eshed Y, Hawker NP, Izhaki A, Baum SF, Bowman JL: Radial patterning of Arabidopsis shoots by class III HD-ZIP and KANADI genes. Curr Biol 2003, 13:1768-1774.

8. Prigge MJ, Otsuga D, Alonso JM, Ecker JR, Drews GN, Clark SE: Class III homeodomain-leucine zipper gene family members have overlapping, antagonistic, and distinct roles in Arabidopsis development. Plant Cell 2005, 17:61-76.

9. Aida M, Ishida T, Fukaki H, Fujisawa H, Tasaka M: Genes involved in organ separation in Arabidopsis: an analysis of the cup-shaped cotyledon mutant. Plant Cell 1997, 9:841-857.

10. Vroemen CW, Mordhorst AP, Albrecht C, Kwaaitaal MACJ, de Vries SC: The CUP-SHAPED COTYLEDON3 gene is required for boundary and shoot meristem formation in Arabidopsis. Plant Cell 2003, 15:1563-1577.

11. Hibara K, Karim MR, Takada S, Taoka K, Furutani M, Aida M, Tasaka M: Arabidopsis CUP-SHAPED COTYLEDON3 regulates postembryonic shoot meristem and organ boundary formation. Plant Cell 2006, 18:2946-2957.

12. Raman S, Greb T, Peaucelle A, Blein T, Laufs P, Theres K: Interplay of miR164, CUP-SHAPED COTYLEDON genes and LATERAL SUPPRESSOR controls axillary meristem formation in Arabidopsis thaliana. Plant J 2008, 55:65-76.

13. Takada S, Hibara K, Ishida T, Tasaka M: The CUP-SHAPED COTYLEDON1 gene of Arabidopsis regulates shoot apical meristem formation. Development 2001, 128:1127-1135.

14. Heisler MG, Ohno C, Das P, Sieber P, Reddy GV, Long JA, Meyerowitz EM: Patterns of auxin transport and gene expression during primordium development revealed by live imaging of the Arabidopsis inflorescence meristem. Curr Biol 2005, 15:1899-1911.

15. McConnell JR, Emery J, Eshed Y, Bao N, Bowman J, Barton MK: Role of PHABULOSA and PHAVOLUTA in determining radial patterning in shoots. Nature 2001, 411:709-713.

16. Kerstetter RA, Bollman K, Taylor RA, Bomblies K, Poethig RS: KANADI regulates organ polarity in Arabidopsis. Nature 2001, 411:706-709.

17. Eshed Y, Baum SF, Perea JV, Bowman JL: Establishment of polarity in lateral organs of plants. Curr Biol 2001, 11:1251-1260.

18. Eshed Y, Izhaki A, Baum SF, Floyd SK, Bowman JL: Asymmetric leaf development and blade expansion in Arabidopsis are mediated by KANADI and YABBY activities. Development 2004, 131:2997-3006.
19. Izhaki A, Bowman JL: KANADI and class III HD-Zip gene families regulate embryo patterning and modulate auxin flow during embryogenesis in Arabidopsis. Plant Cell 2007, 19:495-508

20. Green KA, Prigge MJ, Katzman RB, Clark SE: CORONA, a member of the class III homeodomain leucine zipper gene family in Arabidopsis, regulates stem cell specification and organogenesis. Plant Cell 2005, 17:691-704.

21. Kim J, Jung JH, Reyes JL, Kim YS, Kim SY, Chung KS, Kim JA, Lee M, Lee Y, Narry KV, Chua NH, Park CM: microRNA-directed cleavage of ATHB15 mRNA regulates vascular development in Arabidopsis inflorescence stems. Plant J 2005, 42:84-94.

22. Williams L, Grigg SP, Xie M, Christensen S, Fletcher JC: Regulation of Arabidopsis shoot apical meristem and lateral organ formation by microRNA miR166g and its AtHD-ZIP target genes. Development 2005, 132:3657-3668.

23. Aida M, Tasaka M: Genetic control of shoot organ boundaries. Curr Opin Plant Biol 2006, 9:72-77.

24. Bilsborough GD, Runions A, Barkoulas M, Jenkins HW, Hasson A, Galinha C, Laufs $\mathrm{P}$, Hay A, Prusinkiewicz P, Tsiantis M: Model for the regulation of Arabidopsis thaliana leaf margin development. Proc Natl Acad Sci U S A 2011, 108:3424-3429.

25. Devitt ML, Stafstrom JP: Cell cycle regulation during growth-dormancy cycles in pea axillary buds. Plant Mol Biol 1995, 29:255-265.

26. Tatematsu K, Ward S, Leyser O, Kamiya Y, Nambara E: Identification of cis-elements that regulate gene expression during initiation of axillary bud outgrowth in Arabidopsis. Plant Physiol 2005, 138:757-766.

27. Martín-Trillo M, Cubas P: TCP genes: a family snapshot ten years later. Trends Plant Sci 2010, 15:31-39.

28. Aguilar-Martínez JA, Poza-Carrión C, Cubas P: Arabidopsis BRANCHED1 acts as an integrator of branching signals within axillary buds. Plant Cell 2007, 19:458-472.

29. Finlayson SA: Arabidopsis TEOSINTE BRANCHED-LIKE 1 regulates axillary bud outgrowth and is homologous to monocot TEOSINTE BRANCHED1. Plant Cell Physiol 2007, 48:667-677.

30. Müller D, Leyser O: Auxin, cytokinin and the control of shoot branching. Ann Bot 2011, 107:1203-1212.

31. Vernoux T, Besnard F, Traas J: Auxin at the shoot apical meristem. Cold Spring Harb Perspect Biol 2010, 2:a001487.

32. Benjamins R, Quint A, Weijers D, Hooykaas P, Offringa R: The PINOID protein kinase regulates organ development in Arabidopsis by enhancing polar auxin transport. Development 2001, 128:4057-4067.

33. Friml J, Yang X, Michniewicz M, Weijers D, Quint A, Tietz O, Benjamins R, Ouwerkerk PB, Ljung K, Sandberg G, Hooykaas PJJ, Palme K, Offringa R: A PINOID-dependent binary switch in apical-basal PIN polar targeting directs auxin efflux. Science 2004, 306:862-865.

34. Huang F, Zago MK, Abas L, van Marion A, Galván-Ampudia CS, Offringa R: Phosphorylation of conserved PIN motifs directs Arabidopsis PIN1 polarity and auxin transport. Plant Cell 2010, 22:1129-1142.

35. Bowman JL, Floyd SK: Patterning and polarity in seed plant shoots. Annu Rev Plant Biol 2008, 59:67-88.

36. Vernoux T, Brunoud G, Farcot E, Morin V, Van den Daele H, Legrand J, Oliva M, Das P, Larrieu A, Wells D, Guédon Y, Armitage L, Picard F, Guyomarch S, Cellier C, Parry G, Koumproglou R, Doonan JH, Estelle M, Godin C, Kepinski S, Bennett M, De Veylder L, Traas J: The auxin signalling network translates dynamic input into robust patterning at the shoot apex. Mol Syst Biol 2011, 7:508.

37. Furutani M, Vernoux T, Traas J, Kato T, Tasaka M, Aida M: PIN-FORMED1 and PINOID regulate boundary formation and cotyledon development in Arabidopsis embryogenesis. Development 2004, 131:5021-5030.

38. Zhou GK, Kubo M, Zhong R, Demura T, Ye ZH: Overexpression of miR165 affects apical meristem formation, organ polarity establishment and vascular development in Arabidopsis. Plant Cell Physiol 2007, 48:391-404.

39. Benková E, Michniewicz M, Sauer M, Teichmann T, Seifertová D, Jürgens G, Friml J: Local, efflux-dependent auxin gradients as a common module for plant organ formation. Cell 2003, 115:591-602.

40. Reinhardt D, Pesce ER, Stieger P, Mandel T, Baltensperger K, Bennett M, Traas J, Friml J, Kuhlemeier C: Regulation of phyllotaxis by polar auxin transport. Nature 2003, 426:255-260.

41. Wenzel CL, Schuetz M, Yu Q, Mattsson J: Dynamics of MONOPTEROS and PIN-FORMED1 expression during leaf vein pattern formation in Arabidopsis thaliana. Plant J 2007, 49:387-398. 
42. Ilegems M, Douet V, Meylan-Bettex M, Uyttewaal M, Brand L, Bowman JL, Stieger PA: Interplay of auxin, KANADI and Class III HD-ZIP transcription factors in vascular tissue formation. Development 2010, 137:975-984.

43. Li CJ, Bangerth F: Autoinhibition of indoleaceticacid transport in the shoots of two-branched pea (Pisum sativum) plants and its relationship to correlative dominance. Physiol Plant 1999, 106:415-420.

44. Prusinkiewicz P, Crawford S, Smith RS, Ljung K, Bennett T, Ongaro V, Leyser O: Control of bud activation by an auxin transport switch. Proc Natl Acad Sci U S A 2009, 106:17431-17436.

45. Leyser O: Auxin, self-organisation, and the colonial nature of plants. Curr Biol 2011, 21:R331-R337.

46. Li CJ, Guevara E, Herrera J, Bangerth F: Effect of apex excision and replacement by 1-naphthylacetic acid on cytokinin concentration and apical dominance in pea plants. Physiol Plant 1995, 94:465-469.

47. Tanaka M, Takei K, Kojima M, Sakakibara H, Mori H: Auxin controls local cytokinin biosynthesis in the nodal stem in apical dominance. Plant $J$ 2006, 45:1028-1036.

48. Sachs T, Thimann KV: The role of auxins and cytokinins in the release of buds from dominance. Amer J Bot 1967, 54:136-144.

49. Foo E, Bullier E, Goussot M, Foucher F, Rameau C, Beveridge CA: The branching gene RAMOSUS1 mediates interactions among two nove signals and auxin in pea. Plant Cell 2005, 17:464-474.

50. Gomez-Roldan $V$, Fermas $S$, Brewer PB, Puech-Pagès $V$, Dun EA, Pillot JP, Letisse F, Matusova R, Danoun S, Portais JC, Bouwmeester H, Bécard G, Beveridge CA, Rameau C, Rochange SF: Strigolactone inhibition of shoot branching. Nature 2008, 455:189-194.

51. Umehara M, Hanada A, Yoshida S, Akiyama K, Arite T, Takeda-Kamiya N, Magome H, Kamiya Y, Shirasu K, Yoneyama K, Kyozuka J, Yamaguchi S: Inhibition of shoot branching by new terpenoid plant hormones. Nature 2008, 455:195-200

52. Hayward A, Stirnberg P, Beveridge C, Leyser O: Interactions between auxin and strigolactone in shoot branching control. Plant Physiol 2009, 151:400-412.

53. Brewer PB, Dun EA, Ferguson BJ, Rameau C, Beveridge CA: Strigolactone acts downstream of auxin to regulate bud outgrowth in pea and Arabidopsis. Plant Physiol 2009, 150:482-493.

54. Stirnberg P, Van de Sande K, Leyser HMO: MAX1 and MAX2 control shoot lateral branching in Arabidopsis. Development 2002, 129:1131-1141.

55. Crawford S, Shinohara N, Sieberer T, Williamson L, George G, Hepworth J, Müller D, Domagalska MA, Leyser O: Strigolactones enhance competition between shoot branches by dampening auxin transport. Development 2010, 137:2905-2913

56. Tsuchiya $Y$, Vidaurre D, Toh S, Hanada A, Nambara E, Kamiya $Y$, Yamaguchi S, McCourt P: A small-molecule screen identifies new functions for the plant hormone strigolactone. Nat Chem Biol 2010, 6:741-749.

57. Liu YG, Nagaki K, Fujita M, Kawaura K, Uozumi M, Ogihara Y: Development of an efficient maintenance and screening system for large-insert genomic DNA libraries of hexaploid wheat in a transformationcompetent artificial chromosome (TAC) vector. Plant J 2000, 23:687-695.

58. Hempel FD, Feldman L: Bi-directional inflorescence development in Arabidopsis thaliana: Acropetal initiation of flowers and basipetal initiation of paraclades. Planta 1994, 192:276-286.

59. Chatfield SP, Stirnberg P, Forde BG, Leyser O: The hormonal regulation of axillary bud growth in Arabidopsis. Plant J 2000, 24:159-169.

60. Bennett T, Sieberer T, Willett B, Booker J, Luschnig C, Leyser O: The Arabidopsis MAX pathway controls shoot branching by regulating auxin transport. Curr Biol 2006, 16:553-563.

61. Ulmasov T, Murfett J, Hagen G, Guilfoyle TJ: Aux/IAA proteins repress expression of reporter genes containing natural and highly active synthetic auxin response elements. Plant Cell 1997, 9:1963-1971.

62. Sorefan K, Booker J, Haurogne K, Goussot M, Bainbridge K, Foo E, Chatfield S, Ward S, Beveridge C, Rameau C, Leyser O: MAX4 and RMS1 are orthologous dioxygenase-like genes that regulate shoot branching in Arabidopsis and pea. Genes Dev 2003, 17:1469-1474.

63. Chapman EJ, Estelle M: Mechanism of auxin-regulated gene expression in plants. Annu Rev Genet 2009, 43:265-285.

64. Gray WM, Kepinski S, Rouse D, Leyser O, Estelle M: Auxin regulates SCF ${ }^{\text {TIR1 }}$ dependent degradation of AUX/IAA proteins. Nature 2001, 414:271-276.

65. Lincoln C, Britton JH, Estelle M: Growth and development of the axr mutants of Arabidopsis. Plant Cell 1990, 2:1071-1080.
66. Stirnberg $P$, Chatfield SP, Leyser HMO: AXR1 acts after lateral bud formation to inhibit lateral bud growth in Arabidopsis. Plant Physiol 1999, 121:839-847.

67. Chaudhury AM, Letham S, Craig S, Dennis ES: amp1 - a mutant with high cytokinin levels and altered embryonic pattern, faster vegetative growth, constitutive photomorphogenesis and precocious flowering. Plant Journal 1993, 4:907-916.

68. Chin-Atkins AN, Craig S, Hocart CH, Dennis ES, Chaudhury AM: Increased endogenous cytokinin in the Arabidopsis amp1 mutant corresponds with de-etiolation responses. Planta 1996, 198:549-556.

69. Helliwell CA, Chin-Atkins AN, Wilson IW, Chapple R, Dennis ES, Chaudhury A: The Arabidopsis AMP1 gene encodes a putative glutamate carboxypeptidase. Plant Cell 2001, 13:2115-2125.

70. Saibo NJM, Vriezen WH, De Grauwe L, Azmi A, Prinsen E, Van der Straeten D: A comparative analysis of the Arabidopsis mutant amp1-1 and a novel weak amp1 allele reveals new functions of the AMP1 protein. Planta 2007, 225:831-842.

71. Vidaurre DP, Ploense $S$, Krogan NT, Berleth T: AMP1 and MP antagonistically regulate embryo and meristem development in Arabidopsis. Development 2007, 134:2561-2567.

72. Lin R, Ding L, Casola C, Ripoll DR, Feschotte C, Wang H: Transposasederived transcription factors regulate light signaling in Arabidopsis. Science 2007, 318:1302-1305.

73. Stirnberg P, Zhao S, Williamson L, Ward S, Leyser O: FHY3 promotes shoot branching and stress tolerance in Arabidopsis in an AXR1-dependent manner. Plant J 2012. doi:10.1111/j.1365-313X.2012.05038.x. e-pub ahead of print.

74. Zhang J, Nodzyński T, Pĕnčík A, Rolčík J, Friml J: PIN phosphorylation is sufficient to mediate PIN polarity and direct auxin transport. Proc Nat Acad Sci U S A 2010, 107:918-922.

75. Bennett SRM, Alvarez J, Bossinger G, Smyth DR: Morphogenesis in pinoid mutants of Arabidopsis thaliana. Plant J 1995, 8:505-520.

76. Cheng Y, Qin G, Dai X, Zhao Y: NPY1, a BTB-NPH3-like protein, plays a critical role in auxin-regulated organogenesis in Arabidopsis. Proc Natl Acad Sci U S A 2007, 104:18825-18829.

77. Kleinboelting N, Huep G, Kloetgen A, Viehoever P, Weisshaar B: GABI-Kat SimpleSearch: new features of the Arabidopsis thaliana T-DNA mutant database. Nucleic Acids Res 2012, 40:D1211-D1215.

78. Barakat A, Szick-Miranda K, Chang IF, Guyot R, Blanc G, Cooke R, Delseny M, Bailey-Serres J: The organization of cytoplasmic ribosomal protein genes in the Arabidopsis genome. Plant Physiol 2001, 127:398-415.

79. Baerenfaller K, Grossmann J, Grobei MA, Hull R, Hirsch-Hoffmann M, Yalovsky S, Zimmermann P, Grossniklaus U, Gruissem W, Baginsky S: Genome-scale proteomics reveals Arabidopsis thaliana gene models and proteome dynamics. Science 2008, 320:938-941.

80. Lecompte O, Ripp R, Thierry JC, Moras D, Poch O: Comparative analysis of ribosomal proteins in complete genomes: an example of reductive evolution at the domain scale. Nucleic Acids Res 2002, 30:5382-5390.

81. Ferreira-Cerca S, Pöll G, Gleizes PE, Tschochner H, Milkereit P: Roles of eukaryotic ribosomal proteins in maturation and transport of pre-18S rRNA and ribosome function. Mol Cell 2005, 20:263-275.

82. Rabl J, Leibundgut M, Ataide SF, Haag A, Ban N: Crystal structure of the eukaryotic $40 \mathrm{~S}$ ribosomal subunit in complex with initiation factor 1. Science 2011, 331:730-736.

83. Westermann $\mathrm{P}$, Nygård $\mathrm{O}$ : The spatial arrangement of the complex between eukaryotic initiation factor elF-3 and $40 \mathrm{~S}$ ribosomal subunit. Crosslinking between factor and ribosomal proteins. Biochim Biophys Acta 1983, 741:103-108.

84. Hinnebusch AG: elF3: a versatile scaffold for translation initiation complexes. Trends Biochem Sci 2006, 31:553-562.

85. Byrne ME: A role for the ribosome in development. Trends Plant Sci 2009 , 14:512-519.

86. Creff A, Sormani R, Desnos T: The two Arabidopsis RPS6 genes, encoding for cytoplasmic ribosomal proteins S6, are functionally equivalent. Plant Mol Biol 2010, 73:533-546.

87. Falcone Ferreyra ML, Pezza A, Biarc J, Burlingame AL, Casati P: Plant L10 ribosomal proteins have different roles during development and translation under ultraviolet-B stress. Plant Physiol 2010, 153:1878-1894.

88. Horiguchi G, Mollá-Morales A, Pérez-Pérez JM, Kojima K, Robles P, Ponce MR, Micol JL, Tsukaya H: Differential contributions of ribosomal protein genes to Arabidopsis thaliana leaf development. Plant J 2011, 65:724-736. 
89. Rosado A, Sohn EJ, Drakakaki G, Pan S, Swidergal A, Xiong Y, Kang BH, Bressan RA, Raikhel NV: Auxin-mediated ribosomal biogenesis regulates vacuolar trafficking in Arabidopsis. Plant Cell 2010, 22:143-158.

90. Van Minnebruggen A, Neyt P, De Groeve S, Coussens G, Ponce MR, Micol $J$, Van Lijsebettens M: The ang3 mutation identified the ribosomal protein gene $R P L 5 B$ with a role in cell expansion during organ growth. Physiol Plant 2010, 138:91-101.

91. Szakonyi D, Byrne ME: Ribosomal protein L27a is required for growth and patterning in Arabidopsis thaliana. Plant J 2011, 65:269-281.

92. Doherty L, Sheen MR, Vlachos A, Choesmel V, O'Donohue MF, Clinton C, Schneider HE, Sieff CA, Newburger PE, Ball SE, Niewiadomska E, Matysiak M, Glader B, Arceci RJ, Farrar JE, Atsidaftos E, Lipton JM, Gleizes PE, Gazda HT: Ribosomal protein genes RPS10 and RPS26 are commonly mutated in Diamond-Blackfan anemia. Am J Hum Genet 2010, 86:222-228.

93. Freed EF, Bleichert F, Dutca LM, Baserga SJ: When ribosomes go bad: diseases of ribosome biogenesis. Mol Biosyst 2010, 6:481-493.

94. Warner JR, Mclntosh KB: How common are extraribosomal functions of ribosomal proteins? Mol Cell 2009, 34:3-11.

95. Deisenroth C, Zhang Y: Ribosome biogenesis surveillance: probing the ribosomal protein-Mdm2-p53 pathway. Oncogene 2010, 29:4253-4260.

96. Dutt S, Narla A, Lin K, Mullally A, Abayasekara N, Megerdichian C, Wilson FH, Currie T, Khanna-Gupta A, Berliner N, Kutok JL, Ebert BL: Haploinsufficiency for ribosomal protein genes causes selective activation of p53 in human erythroid progenitor cells. Blood 2011, 117:2567-2576.

97. Narla A, Hurst SN, Ebert BL: Ribosome defects in disorders of erythropoiesis. Int J Hematol 2011, 93:144-149.

98. Abel S, Oeller PW, Theologis A: Early auxin-induced genes encode shortlived nuclear proteins. Proc Natl Acad Sci U S A 1994, 91:326-330.

99. Zenser N, Ellsmore A, Leasure C, Callis J: Auxin modulates the degradation rate of Aux/IAA proteins. Proc Natl Acad Sci U S A 2001, 98:11795-11800.

100. Nishimura T, Wada T, Yamamoto KT, Okada K: The Arabidopsis STV1 protein, responsible for translation reinitiation, is required for auxinmediated gynoecium patterning. Plant Cell 2005, 17:2940-2953.

101. Brodersen $P$, Sakvarelidze-Achard L, Bruun-Rasmussen M, Dunoyer $P$, Yamamoto $Y Y$, Sieburth $L$, Voinnet O: Widespread translational inhibition by plant miRNAs and siRNAs. Science 2008, 320:1185-1190.

102. Lanet $E$, Delannoy $E$, Sormani R, Floris $M$, Brodersen $P$, Crété $P$, Voinnet $O$, Robaglia C: Biochemical evidence for translational repression by Arabidopsis microRNAs. Plant Cell 2009, 21:1762-1768.

103. Husbands AY, Chitwood DH, Plavskin Y, Timmermans MCP: Signals and prepatterns: new insights into organ polarity in plants. Genes Dev 2009, 23:1986-1997.

104. Wang CY, Chen YQ, Liu Q: Sculpting the meristem: the roles of miRNAs in plant stem cells. Biochem Biophys Res Commun 2011, 409:363-366.

105. Pinon V, Etchells JP, Rossignol P, Collier SA, Arroyo JM, Martienssen RA, Byrne ME: Three PIGGYBACK genes that specifically influence leaf patterning encode ribosomal proteins. Development 2008, 135:1315-1324.

106. Braybrook SA, Kuhlemeier C: How a plant builds leaves. Plant Cell 2010, 22:1006-1018

107. Yao $Y$, Ling $Q$, Wang $H$, Huang $H$ : Ribosomal proteins promote leaf adaxial identity. Development 2008, 135:1325-1334.

108. Mallory AC, Dugas DV, Bartel DP, Bartel B: MicroRNA regulation of NACdomain targets is required for proper formation and separation of adjacent embryonic, vegetative, and floral organs. Curr Biol 2004, 14:1035-1046.

109. Baker CC, Sieber P, Wellmer F, Meyerowitz EM: The early extra petals1 mutant uncovers a role for microRNA miR164c in regulating petal number in Arabidopsis. Curr Biol 2005, 15:303-315.

110. Sieber P, Wellmer F, Gheyselinck J, Riechmann JL, Meyerowitz EM: Redundancy and specialization among plant microRNAs: role of the MIR164 family in developmental robustness. Development 2007, 134:1051-1060.

111. Byrne ME, Simorowski J, Martienssen RA: ASYMMETRIC LEAVES1 reveals knox gene redundancy in Arabidopsis. Development 2002, 129:1957-1965.

112. Xu B, Li Z, Zhu Y, Wang H, Ma H, Dong A, Huang H: Arabidopsis genes AS1, AS2, and JAG negatively regulate boundary-specifying genes to promote sepal and petal development. Plant Physiol 2008, 146:566-575.

113. Koyama T, Mitsuda N, Seki M, Shinozaki K, Ohme-Takagi M: TCP transcription factors regulate the activities of ASYMMETRIC LEAVES1 and miR164, as well as the auxin response, during differentiation of leaves in Arabidopsis. Plant Cell 2010, 22:3574-3588.
114. Mordhorst AP, Voerman KJ, Hartog MV, Meijer EA, Van Went J, Koornneef M, de Vries SC: Somatic embryogenesis in Arabidopsis thaliana is facilitated by mutations in genes repressing meristematic cell divisions. Genetics 1998, 149:549-563.

115. Rupp HM, Frank M, Werner T, Strnad M, Schmülling T: Increased steady state mRNA levels of the STM and KNAT1 homeobox genes in cytokinin overproducing Arabidopsis thaliana indicate a role for cytokinins in the shoot apical meristem. Plant J 1999, 18:557-563.

116. Mclntosh KB, Bonham-Smith PC: Ribosomal protein gene regulation: what about plants? Can J Bot 2006, 84:342-362.

117. Hammond MC, Wachter A, Breaker RR: A plant 5 S ribosomal RNA mimic regulates alternative splicing of transcription factor IIIA pre-mRNAs. Nat Struct Mol Biol 2009, 16:541-549.

118. Rosado A, Raikhel NV: Application of the gene dosage balance hypothesis to auxin-related ribosomal mutants in Arabidopsis. Plant Signal Behav 2010, 5:450-452.

119. Stirnberg P, Furner IJ, Leyser HMO: MAX2 participates in an SCF complex which acts locally at the node to suppress shoot branching. Plant J 2007, 50:80-94.

120. Woo HR, Chung KM, Park JH, Oh SA, Ahn T, Hong SH, Jang SK, Nam HG: ORE9, an F-box protein that regulates leaf senescence in Arabidopsis. Plant Cell 2001, 13:1779-1790.

121. Liang J, Zhao L, Challis R, Leyser O: Strigolactone regulation of shoot branching in chrysanthemum (Dendranthema grandiflorum). J Exp Bot 2010, 61:3069-3078.

122. Ingolia NT, Ghaemmaghami S, Newman JRS, Weissman JS: Genome-wide analysis in vivo of translation with nucleotide resolution using ribosome profiling. Science 2009, 324:218-223.

123. Leyser HMO, Lincoln CA, Timpte C, Lammer D, Turner J, Estelle M: Arabidopsis auxin-resistance gene $A X R 1$ encodes a protein related to ubiquitin-activating enzyme E1. Nature 1993, 364:161-164.

124. Konieczny A, Ausubel FM: A procedure for mapping Arabidopsis mutations using co-dominant ecotype-specific PCR-based markers. Plant J 1993, 4:403-410

125. Neff MM, Neff JD, Chory J, Pepper AE: dCAPS, a simple technique for the genetic analysis of single nucleotide polymorphisms: experimental applications in Arabidopsis thaliana genetics. Plant J 1998, 14:387-392.

126. Clough SJ, Bent AF: Floral dip: a simplified method for Agrobacteriummediated transformation of Arabidopsis thaliana. Plant J 1998, 16:735-743.

127. Gleave AP: A versatile binary vector system with a T-DNA organisational structure conducive to efficient integration of cloned DNA into the plant genome. Plant Mol Biol 1992, 20:1203-1207.

\section{doi:10.1186/1471-2229-12-160}

Cite this article as: Stirnberg et al: Mutation of the cytosolic ribosomal protein-encoding RPS1OB gene affects shoot meristematic function in Arabidopsis. BMC Plant Biology 2012 12:160.

\section{Submit your next manuscript to BioMed Central and take full advantage of:}

- Convenient online submission

- Thorough peer review

- No space constraints or color figure charges

- Immediate publication on acceptance

- Inclusion in PubMed, CAS, Scopus and Google Scholar

- Research which is freely available for redistribution 